\title{
p70 S6 kinase drives ovarian cancer metastasis through multicellular spheroid-peritoneum interaction and P-cadherin / $\beta 1$ integrin signaling activation
}

\author{
Carman Ka Man Ip ${ }^{1}$, Susan Yung², Tak-Mao Chan², Sai-Wah Tsao ${ }^{3}$, Alice Sze \\ Tsai Wong ${ }^{1}$ \\ ${ }^{1}$ School of Biological Sciences, University of Hong Kong, Pokfulam Road, Hong Kong \\ 2 Department of Medicine, University of Hong Kong, Sassoon Road, Hong Kong \\ ${ }^{3}$ Department of Anatomy, University of Hong Kong, Sassoon Road, Hong Kong \\ Correspondence to:
}

Dr. Alice Sze Tsai Wong, email: awong1@hku.hk

Keywords: p70s6k P-cadherin, $\beta 1$ integrin, adhesion, metastasis

Received: May 21, $2014 \quad$ Accepted: August 18, $2014 \quad$ Published: August 21, 2014

\section{ABSTRACT}

Peritoneal dissemination as a manifestation of ovarian cancer is an adverse prognostic factor associated with poor clinical outcome, and is thus a potentially promising target for improved treatment. Sphere forming cells (multicellular spheroids) present in malignant ascites of patients with ovarian cancer represent a major impediment to effective treatment. p70 56 kinase $\left(\right.$ p70 $\left.{ }^{56 K}\right)$, which is a downstream effector of mammalian target of rapamycin, is frequently hyperactivated in human ovarian cancer. Here, we identified $p 70^{\mathrm{s} 6 \mathrm{~K}}$ as an important regulator for the seeding and successful colonization of ovarian cancer spheroids on the peritoneum. Furthermore, we provided evidence for the existence of a novel crosstalk between $P$-cadherin and $\beta 1$ integrin, which was crucial for the high degree of specificity in cell adhesion. In particular, we demonstrated that the upregulation of mature $\beta 1$ integrin occurred as a consequence of P-cadherin expression through the induction of the Golgi glycosyltransferase, ST6Gal-I, which mediated $\beta 1$ integrin hypersialylation.

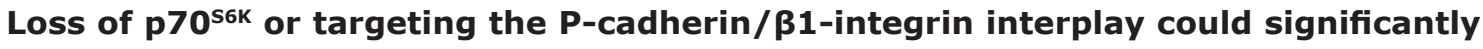
attenuate the metastatic spread onto the peritoneum in vivo. These findings establish a new role for $\mathrm{p70}^{\mathrm{s} 6 \mathrm{~K}}$ in tumor spheroid-mesothelium communication in ovarian cancer and provide a preclinical rationale for targeting ${\mathrm{p} 70^{\mathrm{s}} \mathrm{K}}$ as a new avenue for microenvironment-based therapeutic strategy.

\section{INTRODUCTION}

With approximately 200,000 new cases, and more than 125,000 related deaths occur each year worldwide, ovarian cancer is the most lethal of all gynecologic cancers [1]. The high rate of deaths is due to the large tumor burden with extensive peritoneal metastatic lesions. Despite initial chemosensitivity, ovarian cancer recurrence or peritoneal metastasis results in poor prognosis $(<25 \%)$ and represents a serious clinical challenge. While it is known that localized peritoneal dissemination predominates over hematogenous or lymphatic spread, the exact mechanisms are still unknown. Successful adhesion on the peritoneal mesothelium represents a key rate-limiting step for the onset of the metastatic cascade. Unraveling the underlying molecular pathways is critical for developing new therapeutic strategies.

Emerging basic research, preclinical and clinical findings support the importance of p70 S6 kinase (p70 $\left.0^{\mathrm{S} 6 \mathrm{~K}}\right)$, a downstream effector of mammalian target of rapamycin (mTOR), in the progression of ovarian cancer [2]. Indeed, activation of mTOR is almost ubiquitous in ovarian carcinoma lesions and often correlates with poor prognosis [3]. $\mathrm{p} 70^{\mathrm{S} 6 \mathrm{~K}}$ activation can result from the enhanced expression and activity of cytokines and growth factors, such as hepatocyte growth factor (HGF) that characterizes ovarian cancer [4]. $\mathrm{p} 70^{\mathrm{S} 6 \mathrm{~K}}$ is activated more often in high-grade ovarian carcinomas, which highlights 
the need to understand the role of $\mathrm{p} 70^{\mathrm{s} 6 \mathrm{~K}}$ in ovarian cancer and disease progression [5]. Although the involvement of $\mathrm{p} 70^{\mathrm{S} 6 \mathrm{~K}}$ in the control of growth has been well established, our recent studies showed for the first time that $\mathrm{p} 70^{\mathrm{S} 6 \mathrm{~K}}$ could be involved in other aspects of tumor progression such as metastasis [4, 6]. However, we do not know if $\mathrm{p} 70^{\mathrm{S} 6 \mathrm{~K}}$ plays a role during peritoneal adhesion and dissemination, and if so, how it regulates this process.

Cells propagated to form multicellular spheroids mimic most of the in vivo properties of tumors [7]. This is particularly relevant for ovarian cancer in view of the fact that tumor spheres commonly found in malignant ascites of ovarian cancer patients represent a significant impediment to efficacious treatment [8]. The observation that cancer stem/tumor-initiating cells can also be enriched by spheroids in suspension cultures further suggest spheroid cells may be associated with tumor aggressiveness [9]. Thus, cells cultured as 3D spheroids can be used as a tool to evaluate key metastatic events in the cascade.

Cadherins and integrins are major classes of cell surface receptors that mediate cell-cell and cell-matrix adhesion, respectively [7]. Cadherins, especially E-, N-, and $\mathrm{P}$-cadherin have been implicated in the pathogenesis of ovarian cancer [8], and several integrins are expressed by ovarian tumor cells such as $\alpha 2 \beta 1, \alpha 5 \beta 1$, and $\alpha v \beta 3$ [9]. However, the mechanistic basis of their crosstalk in ovarian cancer is not completely understood.

In this study, we show for the first time a role for $\mathrm{p} 70^{\mathrm{S} 6 \mathrm{~K}}$ in the adhesion and metastatic spread of highly malignant ovarian cancer spheroids into the peritoneum. We also present evidence that a novel interplay linking $\mathrm{P}$-cadherin to regulation of $\beta 1$ integrin activation via the induction of the Golgi glycosyltransferase, ST6Gal-I, which mediates $\beta 1$ integrin hypersialylation in this process.

\section{RESULTS}

\section{$\mathrm{p}^{70}{ }^{\mathrm{S} 6 \mathrm{~K}}$ promotes ovarian cancer spheroid adhesion to peritoneal mesothelium}

The first step in ovarian cancer metastasis is adhesion of cancer cells on the peritoneum. To investigate if $\mathrm{p} 70^{\mathrm{S} 6 \mathrm{~K}}$ plays a role in influencing the adhesion of ovarian cancer cells to the peritoneum, we used a fluorescentbased coculture assay to monitor the interactions between tumor spheroids and primary human mesothelial cells obtained from patients to model the in vivo condition of ovarian cancer. We first examined the intracellular level of $\mathrm{p} 70^{\mathrm{S} 6 \mathrm{~K}}$ by Western blot analysis in three different human ovarian cancer cell lines (CaOV-3, OV-90, and OVCA429) (Figure 1A). CaOV-3 cells showed little expression of active $\mathrm{p} 70^{\mathrm{S} 6 \mathrm{~K}}$, whereas OV-90 and OVCA429 showed strong expression of active $\mathrm{p} 70^{\mathrm{S} 6 \mathrm{~K}}$. We then transfected constitutively activated $\mathrm{p} 70^{\mathrm{S} 6 \mathrm{~K}}$ (myc-tagged $\mathrm{D}_{3} \mathrm{E}_{-} \mathrm{E}_{398}$ ) into $\mathrm{CaOV}-3$ cells. Western blot analysis revealed that $\mathrm{D}_{3} \mathrm{E}_{-} \mathrm{E}_{398}$ increased $\mathrm{p} 70^{\mathrm{S} 6 \mathrm{~K}}$ activity, as indicated by an increase of phosphorylation of S6, a substrate of $\mathrm{p} 70^{\mathrm{S} 6 \mathrm{~K}}$ (Figure 1B, inset). Importantly, ectopic expression of $\mathrm{D}_{3} \mathrm{E}_{-} \mathrm{E}_{398}$ significantly increased adhesion of $\mathrm{CaOV}-3$ spheroids to the mesothelial monolayer (Figure 1B). To confirm the importance of $\mathrm{p} 70^{\mathrm{S} 6 \mathrm{~K}}$ in modulating mesothelial adhesion, we employed a small interfering RNA (siRNA) specifically engineered towards $\mathrm{p} 70^{\mathrm{S} 6 \mathrm{~K}}$. In these studies, HGF was used to activate $\mathrm{p} 70^{\mathrm{S} 6 \mathrm{~K}}$, because HGF is highly expressed in ascitic fluid of ovarian cancer patients, marking it as a major contributor to malignant spreading [10]. We and others have shown that Met tyrosine kinase, a high affinity receptor for $\mathrm{HGF}$, is often overexpressed in ovarian carcinomas and cancer cell lines $[4,11]$, and constitutive activation of the Met receptor through paracrine/autocrine mechanisms has been observed with progressive neoplastic changes [11-13]. The effectiveness of $\mathrm{p} 70^{\mathrm{S} 6 \mathrm{~K}}$-specific siRNA, but not nonspecific siRNA, to deplete $\mathrm{p} 70^{\mathrm{S} 6 \mathrm{~K}}$ expression was confirmed by Western blotting (Figure 1C, inset). Transfection of $\mathrm{p} 70^{\mathrm{S} 6 \mathrm{~K}}$ siRNA in Met-expressing CaOV-3 spheroids inhibited the HGF-mediated adhesion to mesothelial cells (44\% inhibition, $P=0.02$ ) (Figure $1 \mathrm{C}$ ) $[4,11]$. We validated these results using an independent siRNA sequence targeting $\mathrm{p} 70^{\mathrm{S} 6 \mathrm{~K}}$. This effect was similar to the inhibition of cancer spheroid adhesion by rapamycin (40\% inhibition, $P=0.041$ ), a small molecule inhibitor of $\mathrm{p} 70^{\mathrm{S} 6 \mathrm{~K}}$ kinase activity (Figure 1D). To complement our studies, we used two other independent cell lines, OV-90 and OVCA429, which have high basal $\mathrm{p} 70^{\mathrm{S} 6 \mathrm{~K}}$ activities. Spheroid cells treated with $\mathrm{p} 70^{\mathrm{S} 6 \mathrm{~K}}$ siRNA resulted in substantially decreased $\mathrm{p} 70^{\mathrm{S} 6 \mathrm{~K}}$ phosphorylation (OV-90: 75\% inhibition; OVCA429: $86 \%$ inhibition) and $\mathrm{p} 70^{\mathrm{S} 6 \mathrm{~K}}$ expression (OV-90: 72\% inhibition; OVCA429: 93\% inhibition) (Figure 1E \& 1F, inset). The siRNA treated OV-90 and OVCA429 spheroids with reduced $\mathrm{p} 70^{\mathrm{S} 6 \mathrm{~K}}$ levels were incapable of effectively attaching to mesothelial cells, whereas nonspecific siRNA treated spheroids were unaffected (Figure 1E \& 1F). These data suggest that $\mathrm{p} 70^{\mathrm{S} 6 \mathrm{~K}}$ is an important mediator of ovarian cancer spheroid adhesion to the peritoneal mesothelium.

\section{p70 ${ }^{\mathrm{S} 6 \mathrm{~K}}$ activation enhances P-cadherin and $\beta 1$ integrin expression}

To address the mechanism by which $\mathrm{p} 70^{\mathrm{s} 6 \mathrm{~K}}$ signaling could influence cellular adhesion to the mesothelium, we investigated adhesion receptors peritoneal environment as a possible mechanism. We first determined whether p $70^{\text {S6K }}$ activation affected the expression of $\mathrm{N}$ - and P-cadherin present in the ovarian tumor/peritoneal microenvironment [8]. Although $\mathrm{D}_{3} \mathrm{E}_{-} \mathrm{E}_{398}$-expressing CaOV-3 showed increased expression of both $\mathrm{N}$ - and P-cadherin (Figure 2A), depletion of P-cadherin 
A

CaOV-3 OV-90 OVCA429
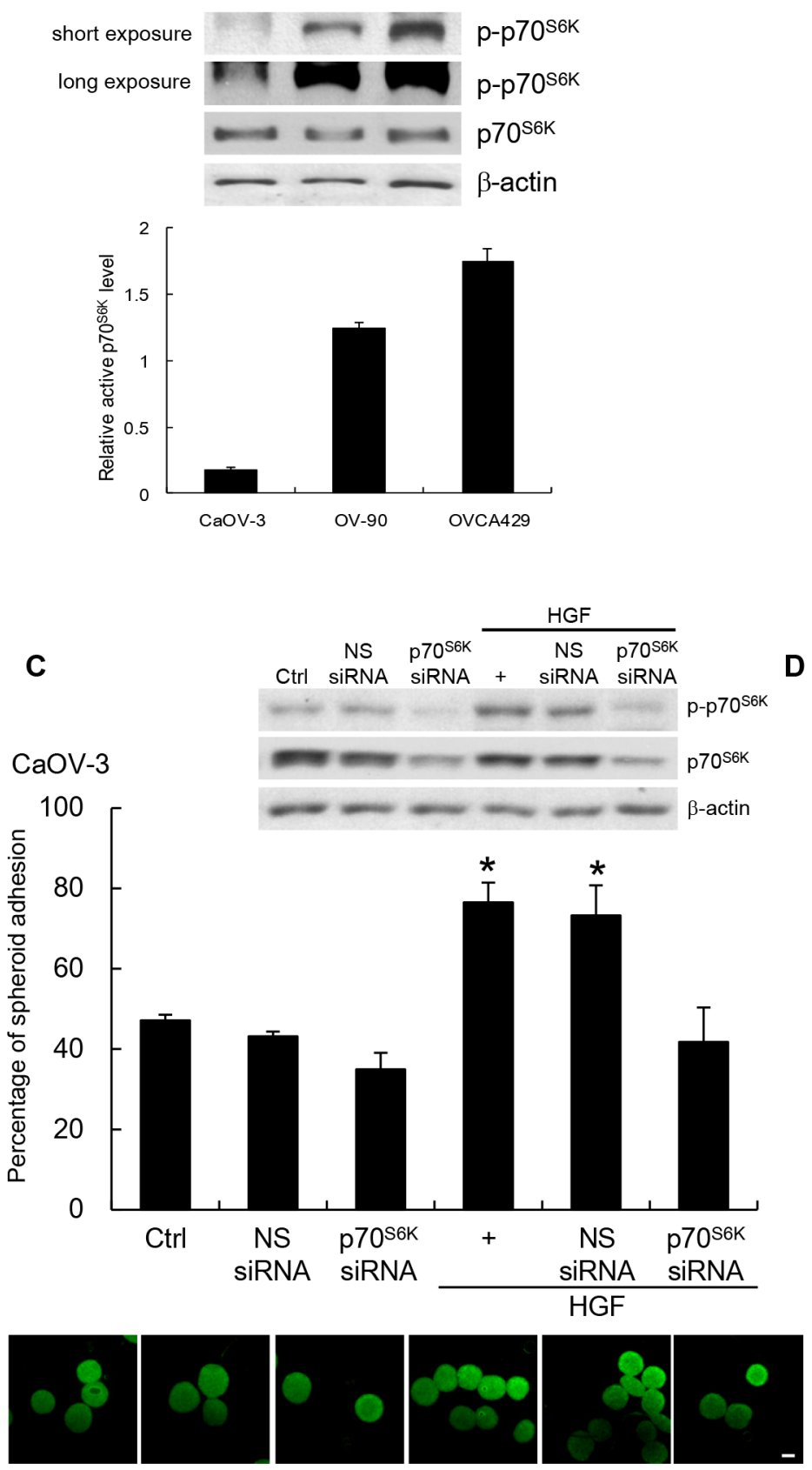

B

D
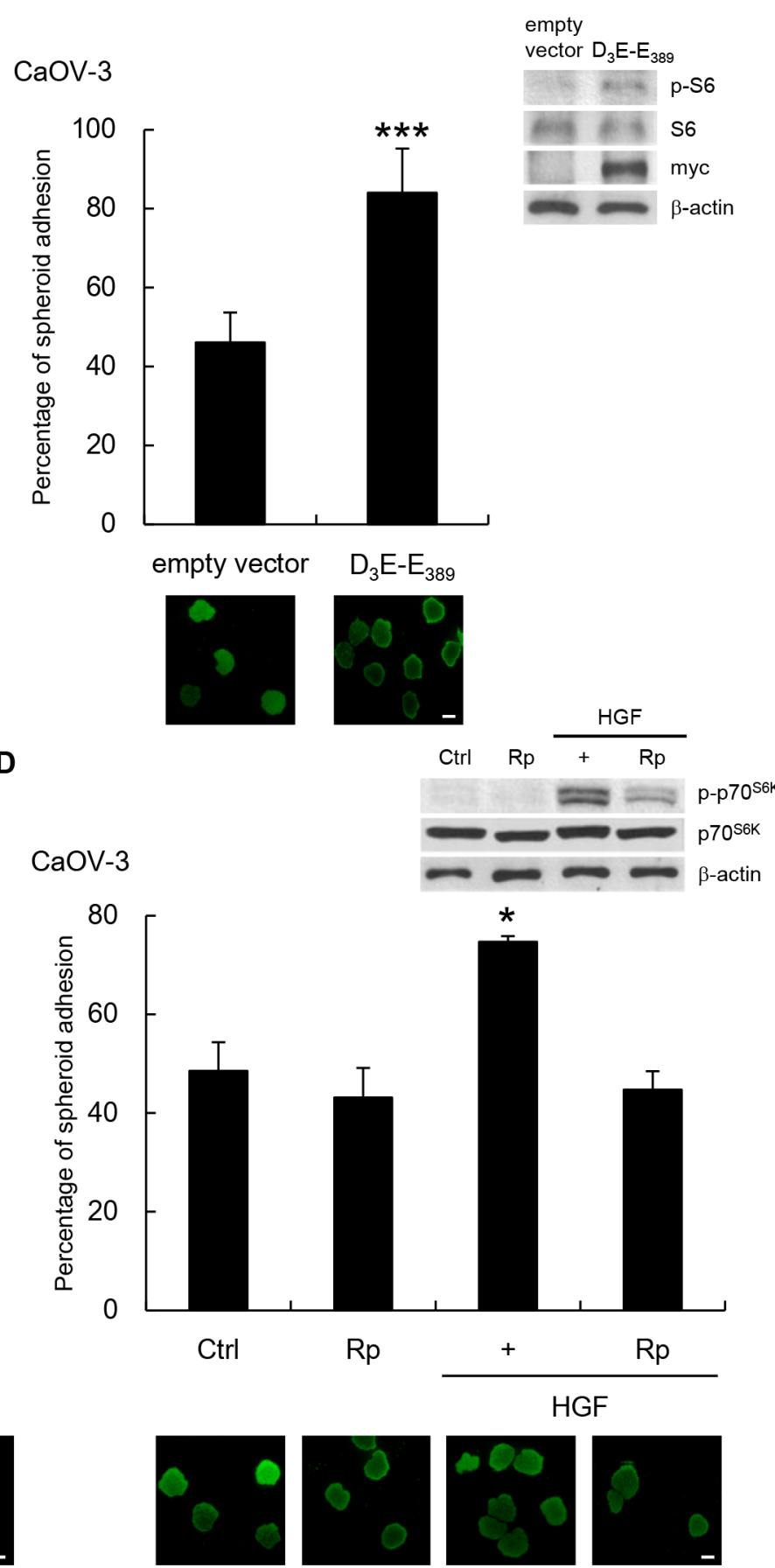

Figure 1: $\mathbf{p 7 0}{ }^{\mathrm{s} 6 \mathrm{~K}}$ activation promotes cancer spheroid adhesion to human peritoneal mesothelial cells. (A) Whole cell lysates were analyzed for levels of phosphorylated (p-) and total $\mathrm{p} 70^{\mathrm{s} 6 \mathrm{~K}}$ by Western blotting with $\beta$-actin was as the loading control. Signal intensity was determined by densitometry, and the level of p-p $70^{\mathrm{s} 6 \mathrm{~K}}$ was normalized against total p $70^{\mathrm{s} 6 \mathrm{~K}}$. (B) Fluorescent-labeled CaOV-3 spheroids transfected with empty vector or myc-tagged constitutively active $\mathrm{p} 70^{\mathrm{s} 6 \mathrm{~K}}\left(\mathrm{D}_{3} \mathrm{E}-\mathrm{E}_{389}\right)$ were plated onto a confluent mesothelium monolayer and allowed to adhere for $5 \mathrm{~h}$. The percentage of adherent spheroids was quantified after nonadherent spheroids were removed. Whole cell lysates were analyzed for levels of phosphorylated (p-) and total S6 and myc by Western blotting (inset). CaOV-3 spheroids (C) expressing nonspecific (NS) or $\mathrm{p} 70^{\mathrm{SGK}}$ siRNA or (D) pretreated with rapamycin (Rp; $20 \mathrm{nM}$ ) before stimulation with hepatocyte growth factor (HGF; $10 \mathrm{ng} / \mathrm{ml}$ ) for $16 \mathrm{~h}$ were harvested for the adhesion assay with mesothelial cells. The activities of $\mathrm{p} 70^{\mathrm{S} 6 \mathrm{~K}}$ were analyzed by Western blotting (inset).

(Continued) 
E

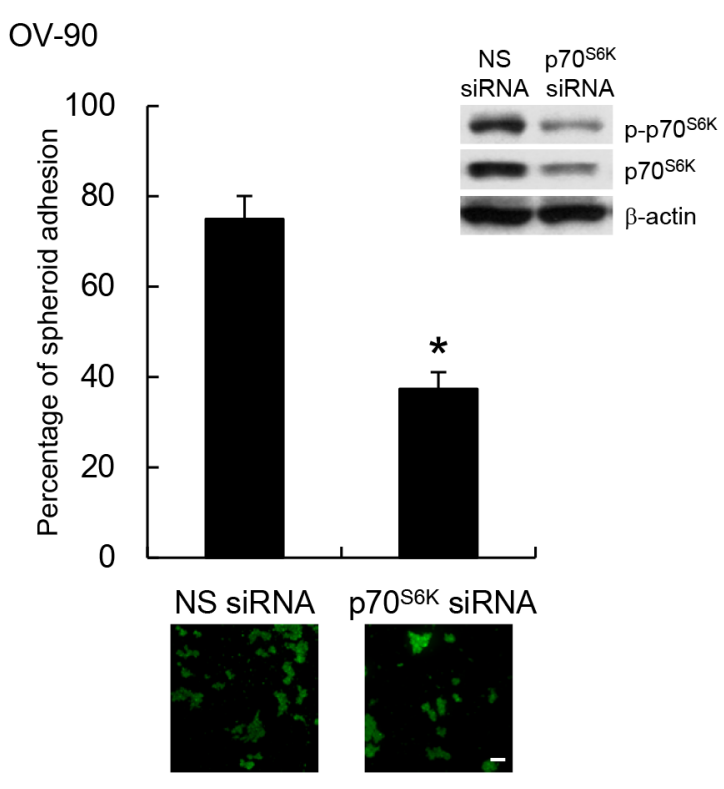

$\mathbf{F}$

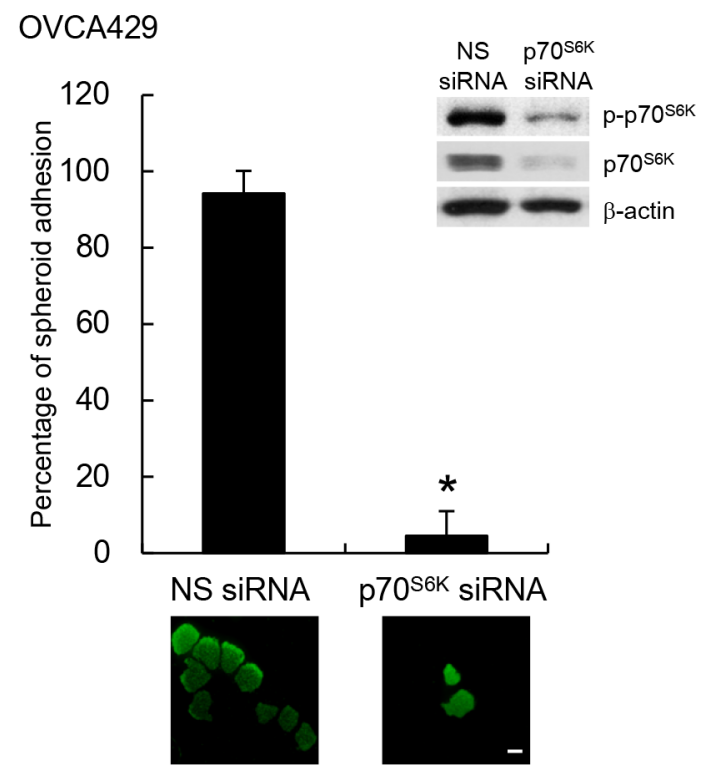

Figure 1: (E) OV-90 or (F) OVCA429 spheroids transfected with NS or p70 $0^{\mathrm{S} 6 \mathrm{~K}}$ siRNA were used in the adhesion assay with mesothelial cells. The knockdown efficiencies of $\mathrm{p} 70^{\mathrm{S} 6 \mathrm{~K}}$ were analyzed by Western blotting (inset). Data are expressed as mean \pm S.D. ${ }^{*}, P<0.05$; **, $P<0.001$ vs. control, empty vector or NS siRNA expressing spheroids.

(Figure 2B, left), but not N-cadherin (Figure 2B, right), resulted in decreased adhesion of $\mathrm{p} 70^{\mathrm{S} 6 \mathrm{~K}}$-expressing cancer spheroids to the mesothelium, whereas treatment with nonspecific siRNA had no effect (Figure 2B). In addition, depletion of $\mathrm{p} 70^{\mathrm{S} 6 \mathrm{~K}}$ in OVCA429 spheroids caused significant decreased $\mathrm{P}$-cadherin expression and inhibited their adhesion to the mesothelium (Figure 2C \& 2D). We also showed that spheroid-mesothelium adhesion was significantly increased in $\mathrm{P}$-cadherin-overexpressing spheroids compared to control spheroids ( $\sim$-fold, $P=0.011$ ), indicating this process was $\mathrm{P}$-cadherin dependent (Figure 2E).

The extracellular matrix (ECM) underlying the mesothelium lies on an (ECM) rich in fibronectin, type I collagen, laminin, and vitronectin [14, 15]. Given the effect of $\mathrm{p} 70^{\mathrm{S} 6 \mathrm{~K}}$ on adhesion to the mesothelium, we set out to assess if $\mathrm{p} 70^{\mathrm{s} 6 \mathrm{~K}}$ could also affect adhesion of cancer spheroids to different ECM components in the peritoneal environment. Compared to empty vector expressing control spheroids, $\mathrm{D}_{3} \mathrm{E}_{-} \mathrm{E}_{398}$-expressing CaOV-3 spheroids had significantly enhanced adhesion to fibronectin (2.4-fold, $P=0.022$ ) and laminin (1.4-fold; $P=0.049$ ), but not to collagen $\mathrm{I}$ or vitronectin (Figure 3A). However, CaOV-3 spheroids treated with $\mathrm{p} 70^{\mathrm{s} 6 \mathrm{~K}}$ siRNA almost completely inhibited HGF-mediated adhesion to fibronectin and laminin (Figure 3B), whereas treatment with nonspecific siRNA had no effect (Figure 3B). Furthermore, treatment with rapamycin also resulted in decreased spheroid attachment onto fibronectin and laminin (Figure 3C). In comparison, OV-90 and OVCA429 spheroids treated wtih $\mathrm{p} 70^{\mathrm{s} 6 \mathrm{~K}}$
siRNA also showed marked decreases in adhesion to fibronectin (OV-90: $36 \%$ inhibition, $P=0.012$; OVCA429: $36 \%$ inhibition, $P=0.045$ ) and laminin (OV-90: 43\% inhibition, $P=0.049$; OVCA429: $80 \%$ inhibition, $P=0.041$ ), whereas treatment with nonspecific siRNA had no effect (Figure 3D \& 3E).

$\beta 1$ integrin is known to be relevant in the process of adhesion to fibronectin and laminin [16]. We found $\beta 1$ integrin expression was significantly enhanced in $\mathrm{D}_{3} \mathrm{E} \mathrm{E}_{398}$-expressing CaOV-3 spheroids (Figure 4A, left), whereas knockdown of $\mathrm{p} 70^{\mathrm{S} 6 \mathrm{~K}}$ resulted in decreased $\beta 1$ integrin expression (Figure 4A, right). Interestingly, these changes in expression occurred in the $130 \mathrm{kDa}$ mature form of $\beta 1$ integrin, which represents the fully glycosylated, functional receptor, but no changes occurred in the $\sim 85-\mathrm{kDa}$ core peptide (Figure 4A). To test the specific involvement of the mature form of $\beta 1$ integrin more directly, we treated $\mathrm{D}_{3} \mathrm{E}_{-} \mathrm{E}_{398}$-expressing $\mathrm{CaOV}-3$ spheroids with blocking antibodies against $\beta 1$ integrin. The inhibition of surface $\beta 1$ integrin specifically inhibited the adhesion of spheroids to fibronectin, laminin (Figure 4B), and primary human mesothelial cells (Figure 4C). The inhibition of $\beta 1$ integrin by specific siRNA treatment also inhibited $70^{\mathrm{S} 6 \mathrm{~K}}$-dependent tumor spheroid attachment to fibronectin, laminin (Figure 4D), and mesothelial cells (Figure 4E). Similarly, $\beta 1$ integrin siRNA-transfected OVCA429 showed significant reduction of spheroid adhesion to fibronectin, laminin (Figure 4F), and mesothelial cells (Figure 4G), which confirms the involvement of mature $\beta 1$ integrin in ovarian cancer spheroid-mesothelium adhesion. 
A

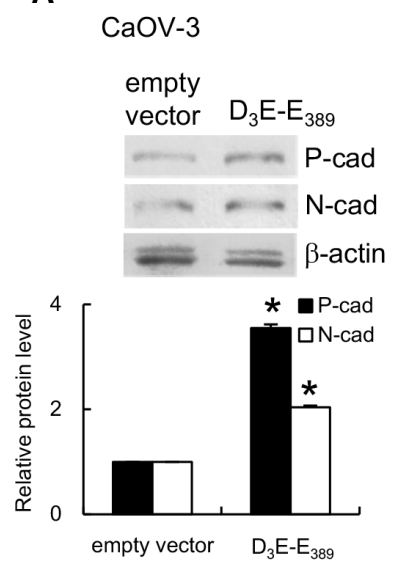

B CaOV-3
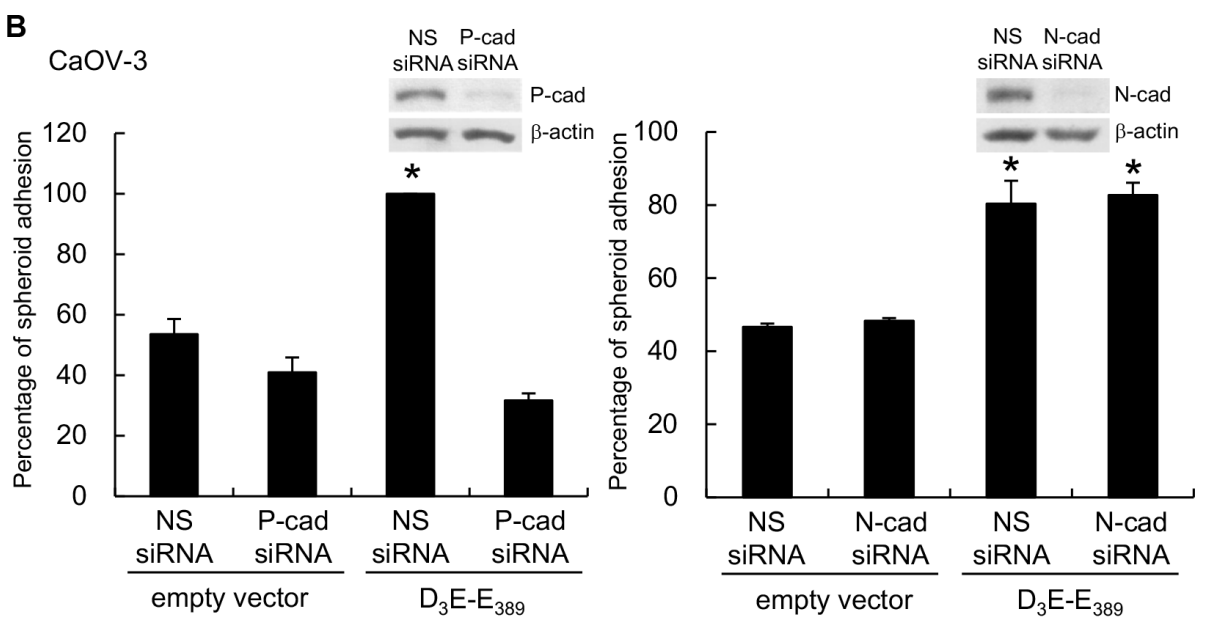

C

OVCA429

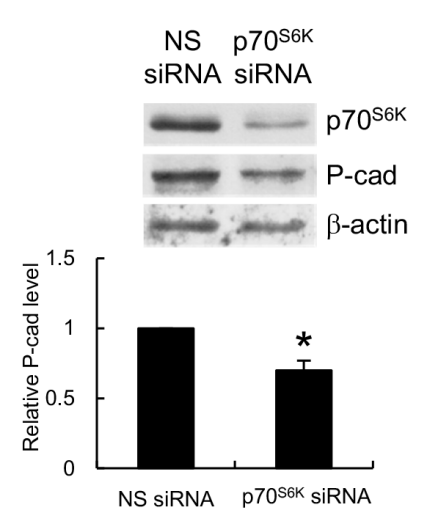

D OVCA429
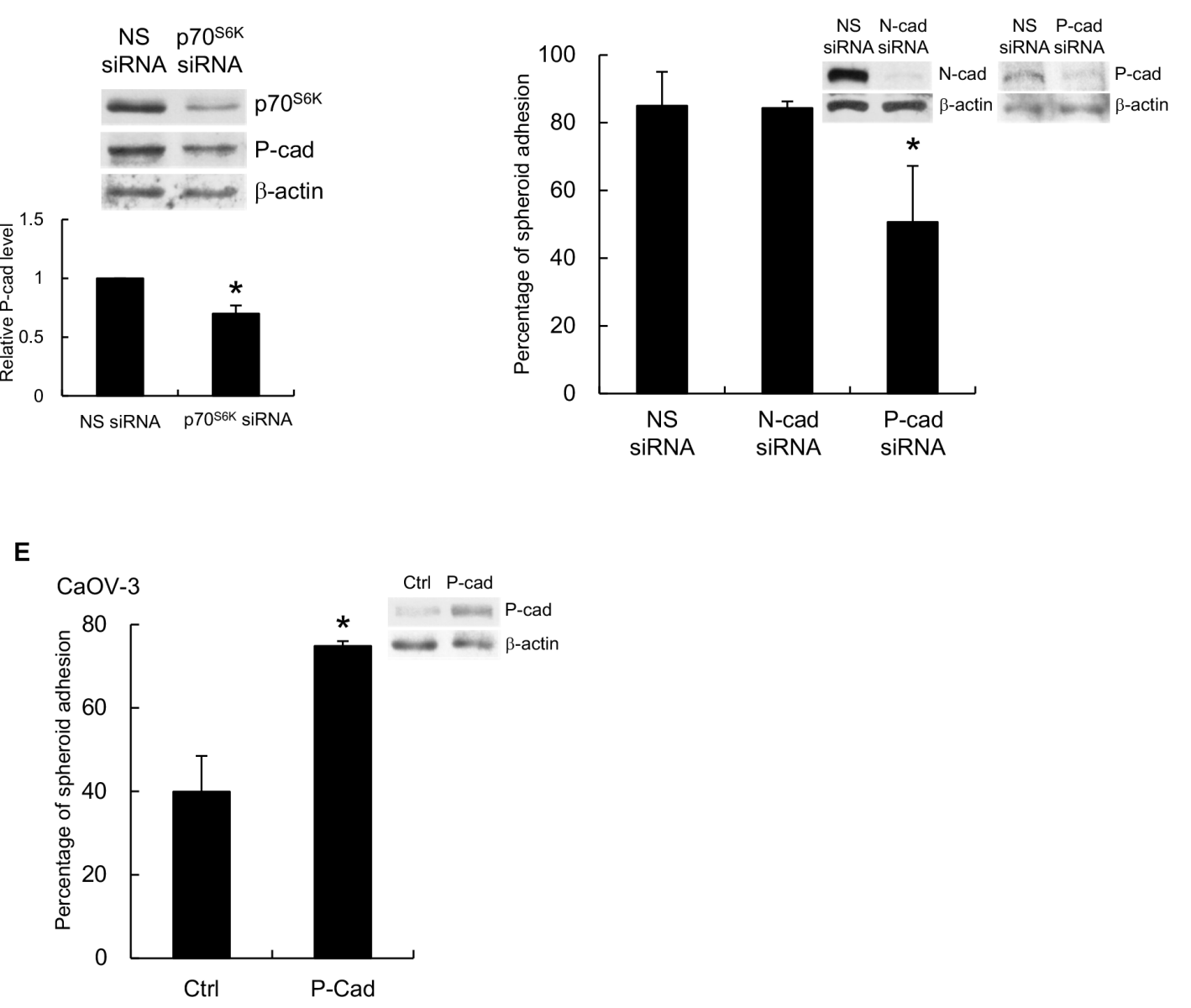

Figure 2: P-cadherin mediates $\mathbf{p} 70^{\mathrm{S} 6 \mathrm{~K}}$-dependent spheroid-mesothelium adhesion. (A) Whole cell lysates of CaOV-3 spheroids transfected with empty vector or myc-tagged constitutively active $\mathrm{p} 70^{\mathrm{S} 6 \mathrm{~K}}\left(\mathrm{D}_{3} \mathrm{E}-\mathrm{E}_{389}\right)$ were analyzed for levels of $\mathrm{N}$ - and P-cadherin by Western blotting with $\beta$-actin as the loading control. The signal intensity was determined by densitometry, and levels of $\mathrm{N}$ - and P-cadherin were normalized against the $\beta$-actin control. (B) Spheroids cotransfected with empty vector or myc-tagged $\mathrm{D}_{3} \mathrm{E}_{-} \mathrm{E}_{389}$ and nonspecific (NS) siRNA, P-cadherin siRNA (left) or N-cadherin siRNA (right) were plated onto a confluent mesothelium monolayer and allowed to adhere for $5 \mathrm{~h}$. The percentage of adherent spheroids was quantified after nonadherent spheroids were removed. (C) The levels of p $70^{\mathrm{s} 6 \mathrm{~K}}$ and P-cadherin in OVCA429 spheroids transfected with NS siRNA or p70 ${ }^{\mathrm{s} 6 \mathrm{~K}}$ siRNA were analyzed by Western blotting. (D) OVCA429 spheroids transfected with NS siRNA, N-cadherin siRNA, or P-cadherin siRNA, and (E) CaOV-3 spheroids stably expressing P-cadherin were harvested for the adhesion assay with mesothelial cells. The expression of P-cadherin was analyzed by Western blotting. Data are expressed as mean \pm S.D. ${ }^{*}, P<0.05$ vs. control, empty vector or NS siRNA expressing spheroids. 
A

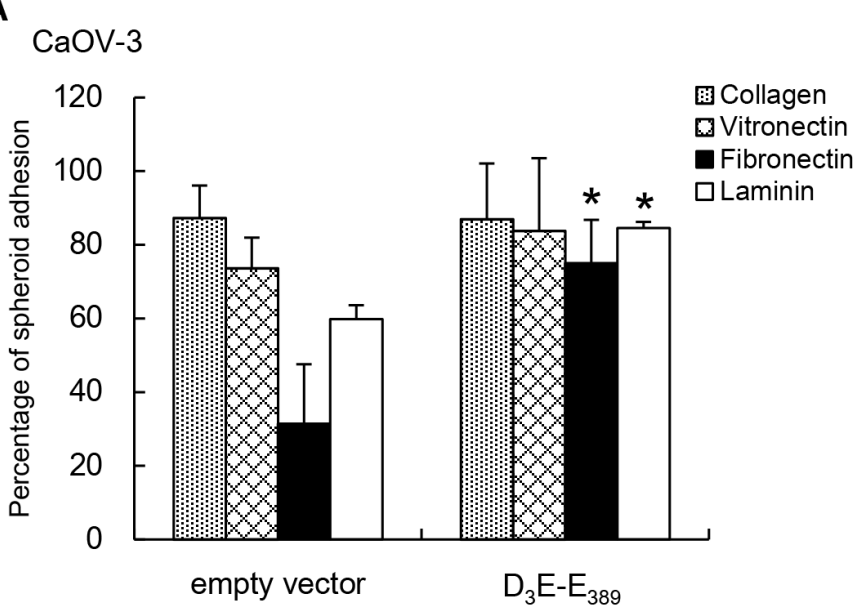

B

CaOV-3

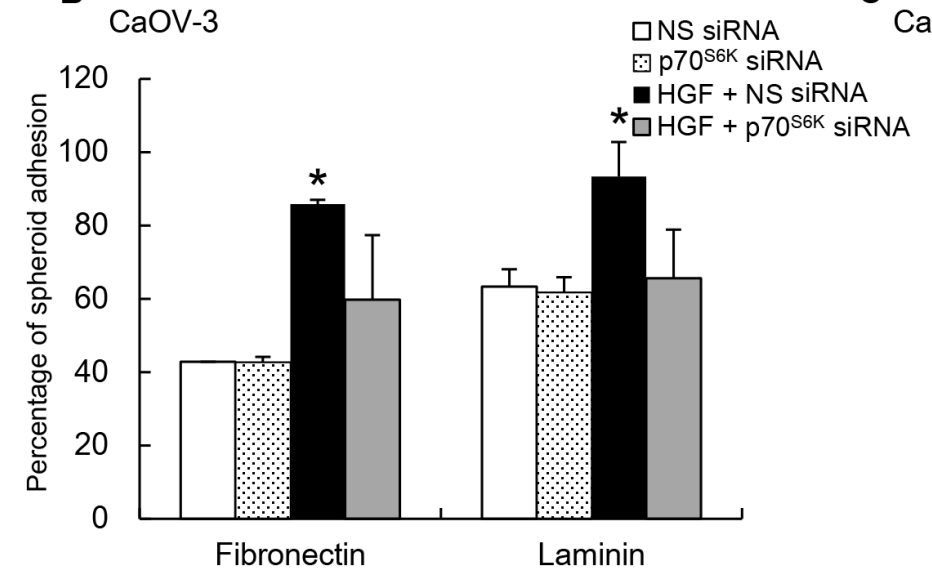

C

CaOV-3

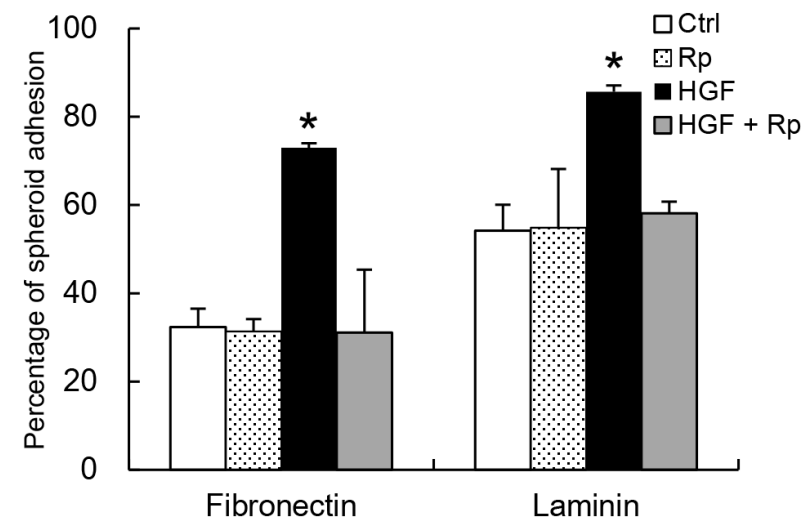

D

OV-90

E

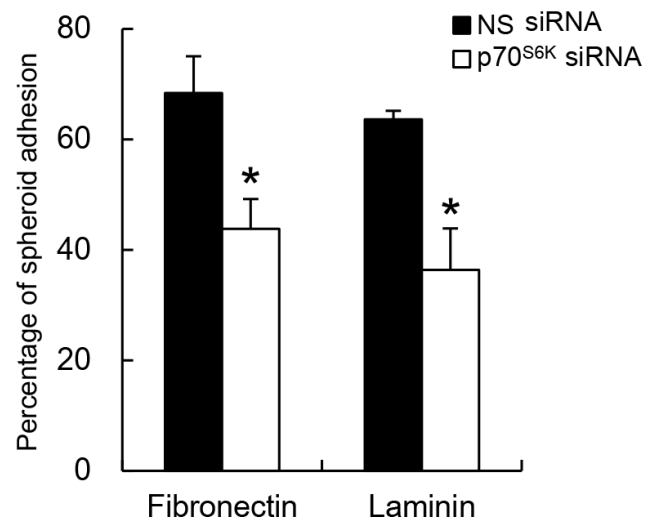

OVCA429

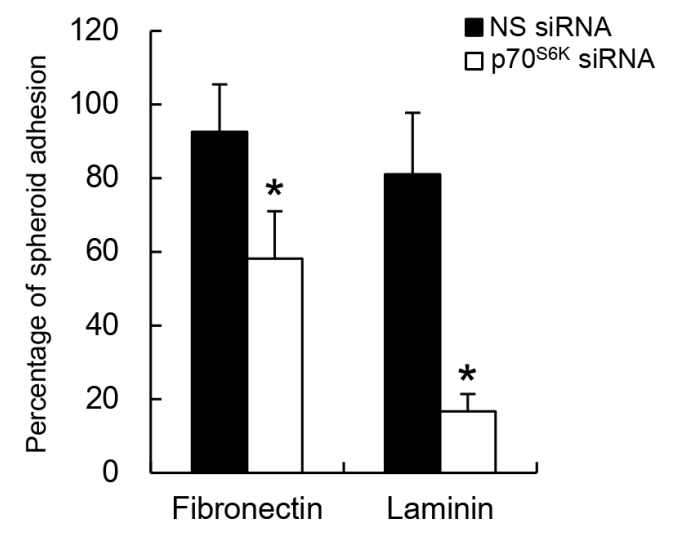

Figure 3: $\mathbf{p 7 0}^{\mathrm{s} 6 \mathrm{~K}}$ activation promotes spheroid adhesion to fibronectin and laminin. (A) CaOV-3 spheroids expressing empty vector or constitutively active $\mathrm{p} 70^{\mathrm{s} 6 \mathrm{~K}}\left(\mathrm{D}_{3} \mathrm{E}-\mathrm{E}_{389}\right)$ plasmid added to plates coated with collagen I, vitronectin, fibronectin, or laminin $(10 \mu \mathrm{g} / \mathrm{ml})$ for $2-5 \mathrm{~h}$. (B) CaOV-3 cells expressing nonspecific (NS) siRNA or $\mathrm{p} 70^{\mathrm{s} 6 \mathrm{~K}}$ siRNA or (C) pretreated with rapamycin (Rp; $20 \mathrm{nM}$ ) before stimulation with hepatocyte growth factor (HGF; $10 \mathrm{ng} / \mathrm{ml}$ ) were used in the adhesion assay with fibronectin or laminin. (D) OV-90 or (E) OVCA429 spheroids transfected with NS siRNA or p70 ${ }^{56 \mathrm{~K}}$ siRNA were used in the adhesion assay with fibronectin or laminin. The percentage of adherent spheroids was quantified after nonadherent spheroids were removed. Data are expressed as mean \pm S.D. * $P<0.05$ vs. control, empty vector or NS siRNA expressing spheroids. 

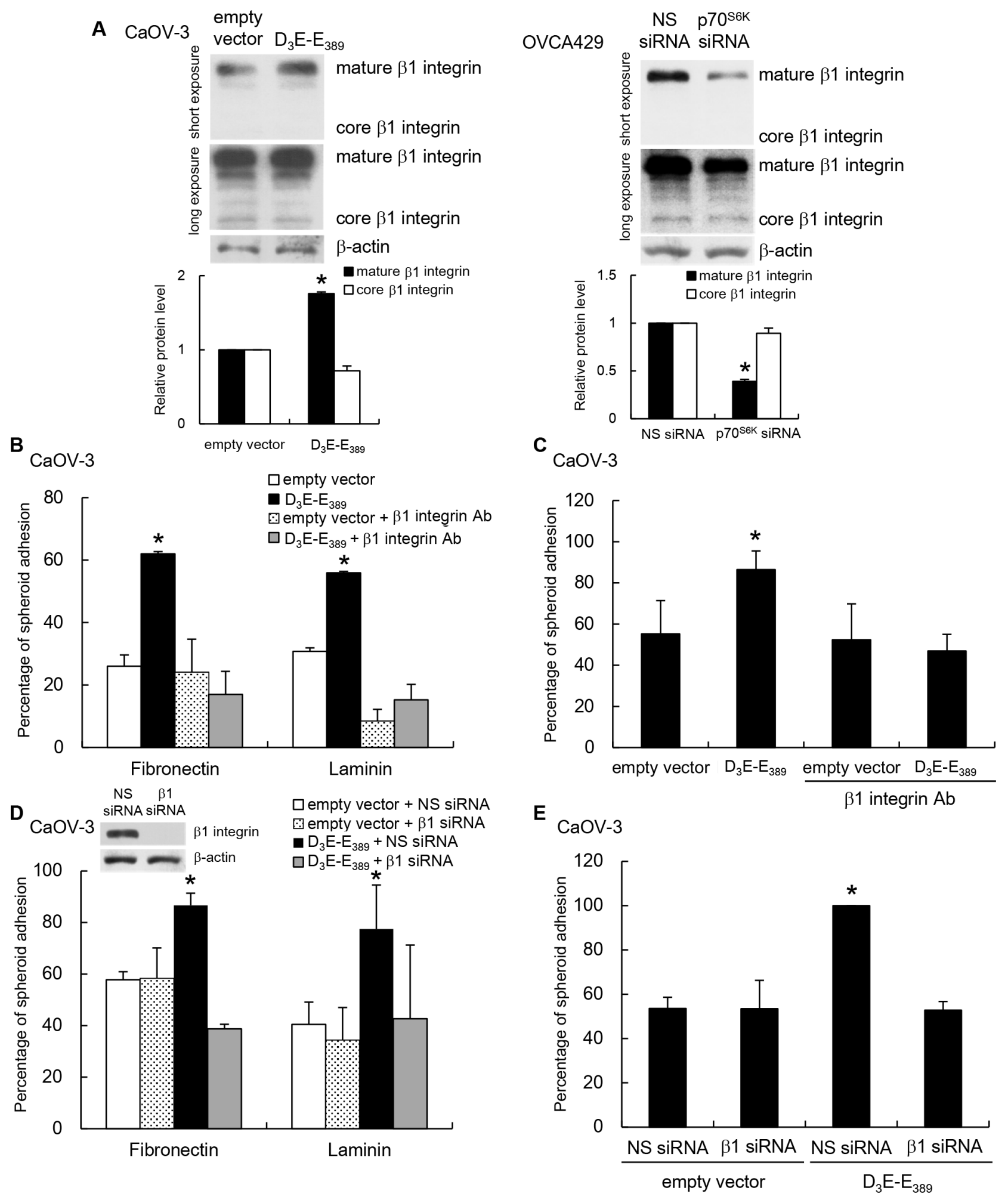

Figure 4: $\mathbf{p 7 0}^{\mathrm{s} 6 \mathrm{~K}}$ regulates $\beta 1$ integrin expression and regulates cancer spheroid-ECM adhesion. (A) Whole cell lysates of CaOV-3 spheroids transfected with empty vector or myc-tagged constitutively active $\mathrm{p} 70^{56 \mathrm{~K}}\left(\mathrm{D}_{3} \mathrm{E}-\mathrm{E}_{389}\right)$ were analyzed for core or mature form of $\beta 1$ integrin expression by Western blotting with $\beta$-actin as the loading control. The signal intensity was determined by densitometry and levels of the core or mature form of $\beta 1$ integrin were normalized against the $\beta$-actin control. (B) Spheroids were preincubated with $\beta 1$ integrin neutralizing antibody ( $\beta 1$ integrin $\mathrm{Ab}$ ) for the adhesion assay with fibronectin, laminin or (C) mesothelial cells. CaOV-3 spheroids cotransfected with empty vector or $\mathrm{D}_{3} \mathrm{E}-\mathrm{E}_{389}$ and nonspecific (NS) siRNA or $\beta 1$ integrin siRNA ( $\beta 1$ siRNA) were used in the adhesion assay with (D) fibronectin, laminin or (E) mesothelial cells.

(Continued) 
$\mathbf{F}$

OVCA429

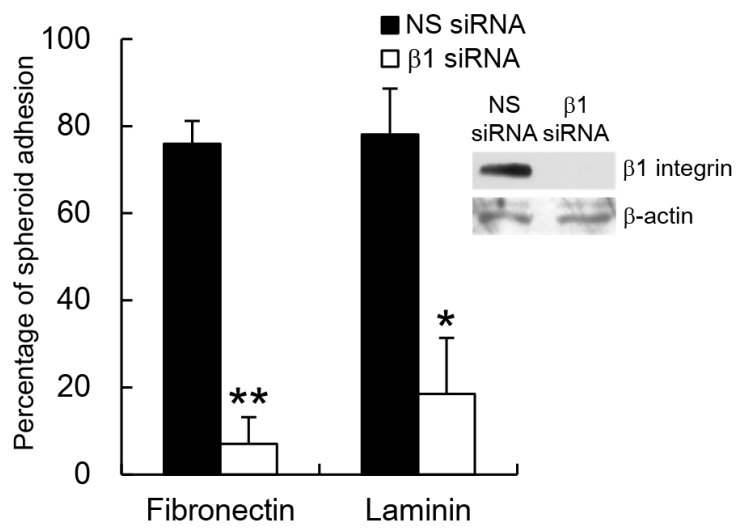

G

OVCA429

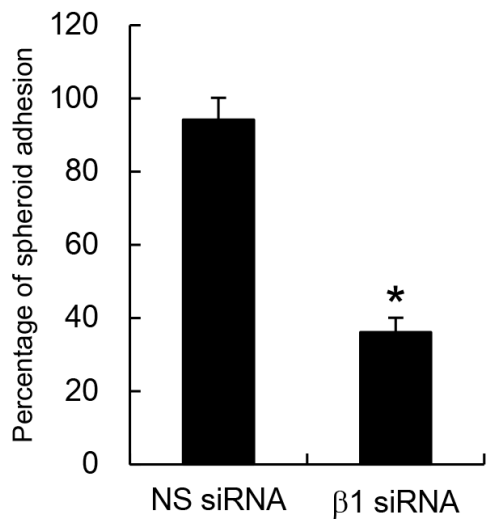

Figure 4: OVCA429 spheroids transfected with NS siRNA or $\beta 1$ integrin siRNA were used in the adhesion assay with (F) fibronectin, laminin or (G) mesothelial cells. The knockdown efficiencies of $\beta 1$ integrin were evaluated by Western blotting (inset). The percentage of adherent spheroids was quantified after nonadherent spheroids were removed. Data are expressed as mean \pm S.D. ${ }^{*}, P<0.05 ; * *, P<0.005$ vs. empty vector or NS siRNA expressing spheroids.

\section{A}

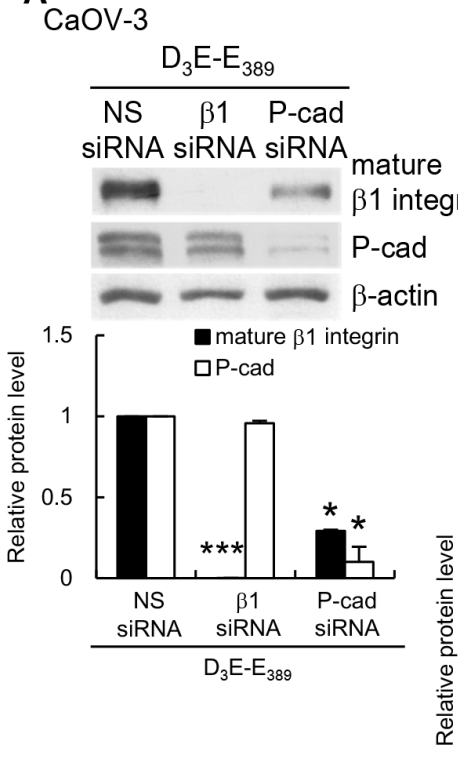

CaOV-3

$$
\begin{array}{cc}
\mathrm{D}_{3} \mathrm{E}-\mathrm{E}_{389} \\
\text { NS P-cad }
\end{array}
$$
siRNA siRNA

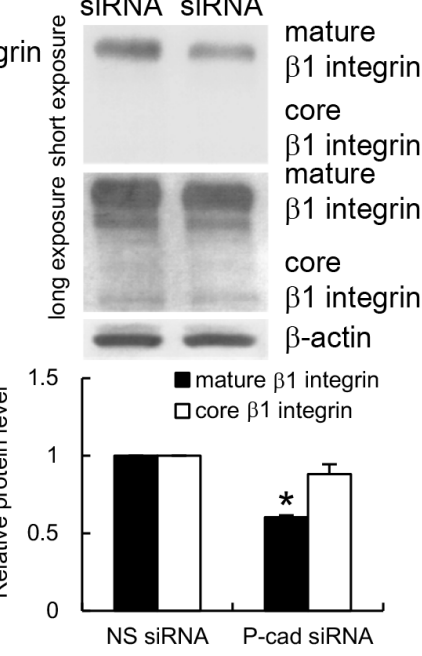

\section{OVCA429}

NS P-cad SiRNA SIRNA
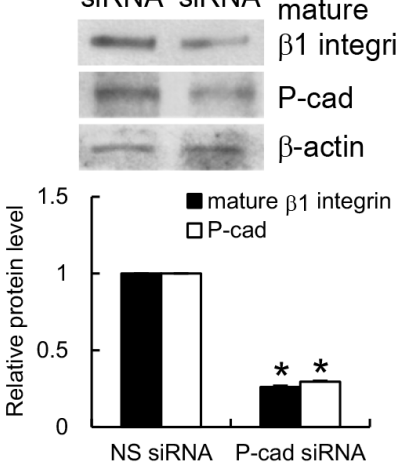

NS $\quad \beta 1$ siRNA siRNA

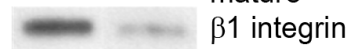

$\longrightarrow$ P-cad

$\longrightarrow \beta$-actin

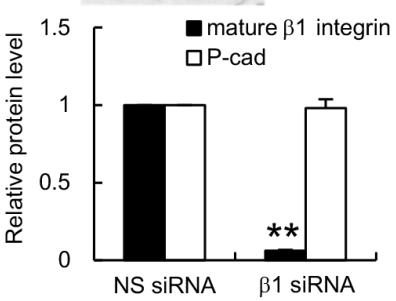

Figure 5: P-cadherin acts upstream of $\beta 1$ integrin to mediate $\mathbf{p 7 0}^{\mathrm{s} 6 \mathrm{~K}}$-dependent adhesion. (A) CaOV-3 spheroids cotransfected with constitutively active $\mathrm{p} 70^{\mathrm{S} 6 \mathrm{~K}}\left(\mathrm{D}_{3} \mathrm{E}-\mathrm{E}_{389}\right)$ and nonspecific (NS) siRNA, $\beta 1$ integrin siRNA ( $\beta 1$ siRNA), or P-cadherin siRNA, and (B) OVCA429 spheroids transfected NS siRNA, $\beta 1$ integrin siRNA, or P-cadherin siRNA were analyzed for core or mature forms of $\beta 1$ integrin and P-cadherin by Western blotting with $\beta$-actin as the loading control. The signal intensity was determined by densitometry, and levels of P-cadherin and the core or mature forms of $\beta 1$ integrin were normalized against the $\beta$-actin control.

(Continued)

\section{P-cadherin functions upstream of $\beta 1$ integrin in $\mathrm{p}^{70^{\mathrm{S} 6 \mathrm{~K}}}$ signaling}

To investigate the possible crosstalk between P-cadherin and $\beta 1$ integrin and to determine their interdependency, we examined the effect of P-cadherin and $\beta 1$ integrin siRNAs on the expression of the two adhesion receptors in $\mathrm{D}_{3} \mathrm{E}_{-} \mathrm{E}_{389}$-expressing $\mathrm{CaOV}-3$ spheroids. Knocking down $\beta 1$ integrin did not affect P-cadherin expression (Figure 5A). However, depletion of $\mathrm{P}$-cadherin did affect $\beta 1$ integrin expression (Figure $5 \mathrm{~A}$ ), but only the expression of the mature $\beta 1$ integrin was inhibited and not core $\beta 1$ integrin (Figure 5A). For comparison, we also used OVCA429 spheroids, which gave us similar results (Figure 5B). Accordingly, treatment of CaOV-3 spheroids with P-cadherin siRNA abolished 

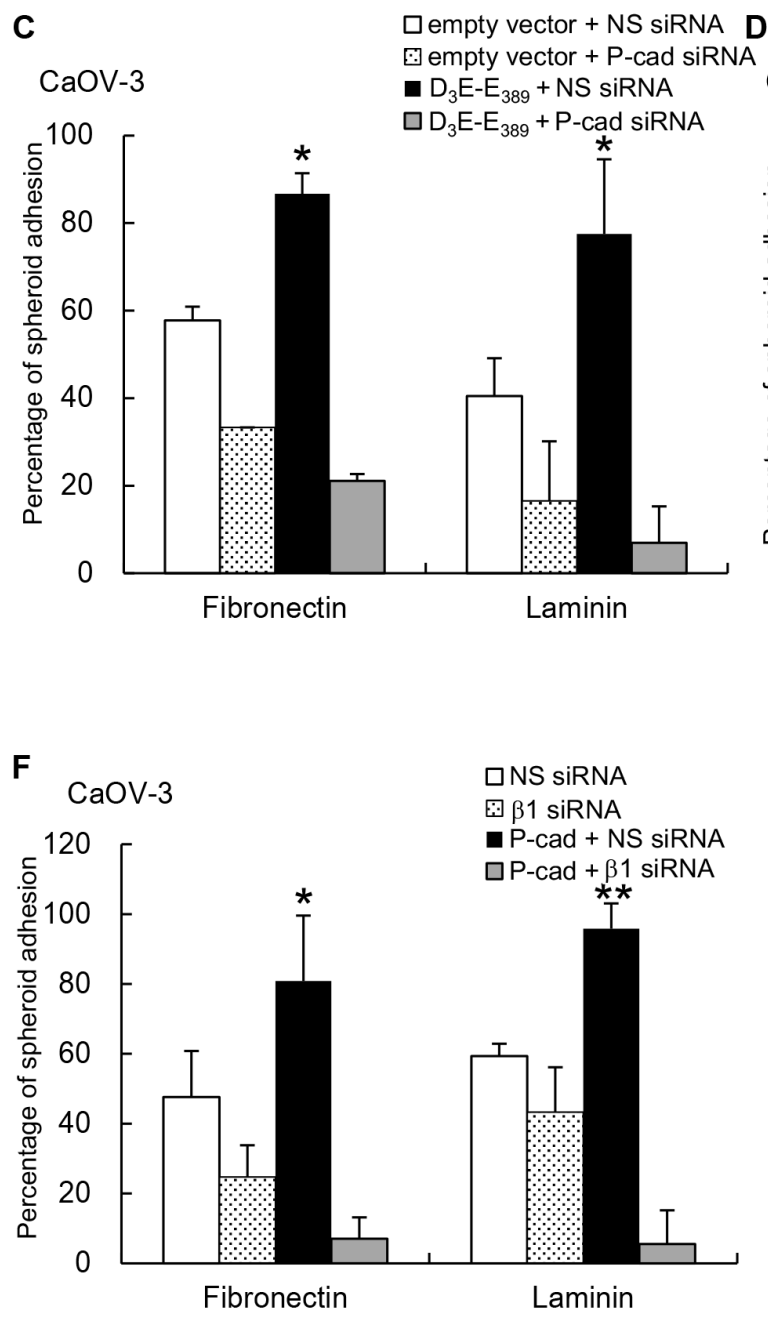

G

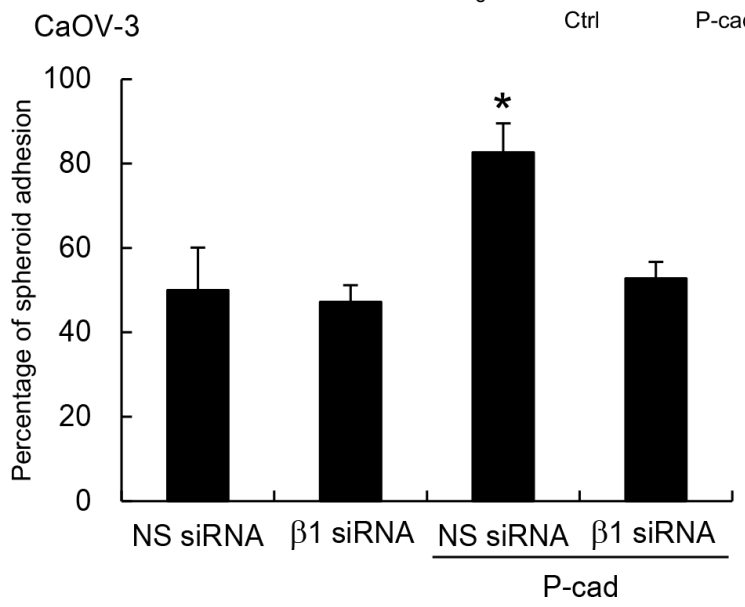

Figure 5: (C) $\mathrm{D}_{3} \mathrm{E}_{-} \mathrm{E}_{389}$-expressing CaOV-3 or (D) OVCA429 spheroids transfected with NS siRNA or P-cadherin siRNA were used in the adhesion assay with fibronectin or laminin. (E) CaOV-3 stably expressing P-cadherin were analyzed for core or mature forms of $\beta 1$ integrin by Western blotting with $\beta$-actin as the loading control. P-cadherin-expressing CaOV-3 transfected with NS siRNA or $\beta 1$ integrin siRNA were collected for the adhesion assay with (F) fibronectin, laminin or (G) mesothelial cells. The percentage of adherent spheroids was quantified after nonadherent spheroids were removed. Data are expressed as mean \pm S.D. *,$P<0.05 ; * *, P<0.005 ;{ }^{* * *}, P<0.001$ vs. empty vector or NS siRNA expressing spheroids.

$\mathrm{D}_{3} \mathrm{E}-\mathrm{E}_{389}-$ mediated adhesion to fibronectin and laminin (Figure 5C), and again similar results were observed with OVCA429 spheroids (Figure 5D). Ectopic expression of P-cadherin significantly increased the levels of the mature $\beta 1$ integrin, but not core $\beta 1$ integrin (Figure 5E). After transfection with $\beta 1$ integrin siRNA, P-cadherinoverexpressing $\mathrm{CaOV}-3$ spheroids were unable to adhere to fibronectin, laminin (Figure 5F), and mesothelial cells (Figure 5G). The nonspecific siRNA treatment had no effect. Together, these observations raise the intriguing possibility that P-cadherin could affect the posttranslational events of $\beta 1$ integrin, and subsequently its activity in ovarian cancer cells.

$\mathrm{N}$-glycans of $\beta 1$ integrin are known to have a different carbohydrate compositions after cell transformation [17]. Recent studies suggest that $\beta 1$ integrin is a substrate for the Golgi glycosyltransferase, ST6Gal-I $[18,19]$. To investigate more in detail the regulation of $\beta 1$ integrin by P-cadherin, we tested the involvement of ST6Gal-I. A strong induction of ST6Gal-1 was observed in $\mathrm{p} 70^{\mathrm{S} 6 \mathrm{~K}}$-expressing $\mathrm{CaOV}-3$ spheroids (Figure 6A), which was markedly reduced with P-cadherin siRNA treatment, but nonspecific siRNA treatment had no effect (Figure 6B). In support, knockdown of $\mathrm{p} 70^{\mathrm{S} 6 \mathrm{~K}}$ (Figure 6C) or P-cadherin (Figure 6D) in OVCA429 significantly inhibited ST6Gal-I expression, whereas overexpression of P-cadherin in CaOV-3 enhanced ST6Gal-I expression (Figure 6E). The knockdown of ST6Gal-I significantly inhibited the P-cadherin-induced mature $\beta 1$ integrin expression (Figure 6F), indicating that ST6Gal-I was 
A

CaOV-3

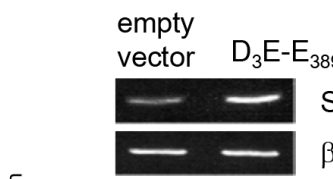

ST6Gal-I

$\beta$-actin

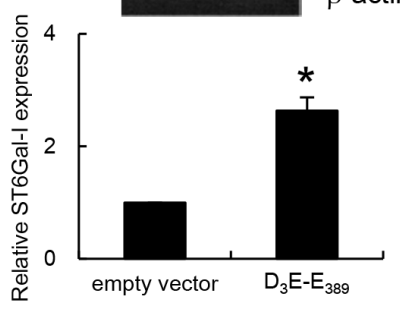

D

OVCA429

NS P-cad

SiRNA siRNA
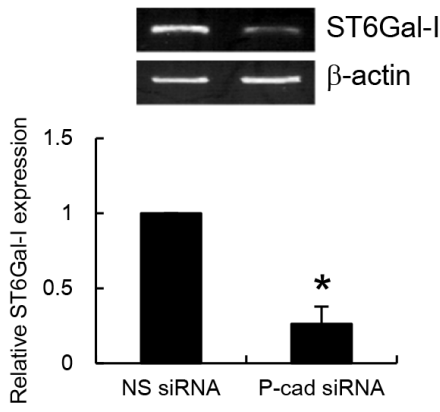

B

CaOV-3
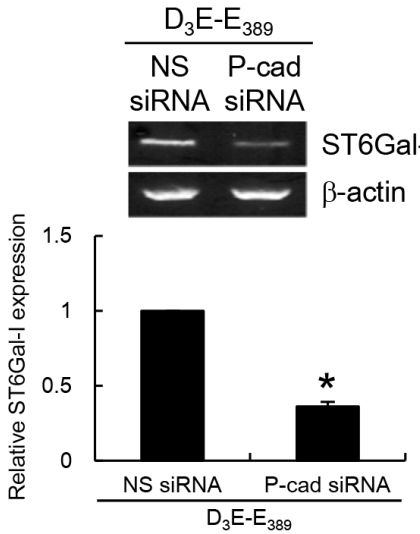

E

CaOV-3
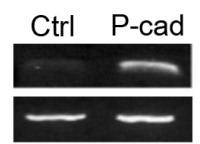

ST6Gal-I

$\beta$-actin

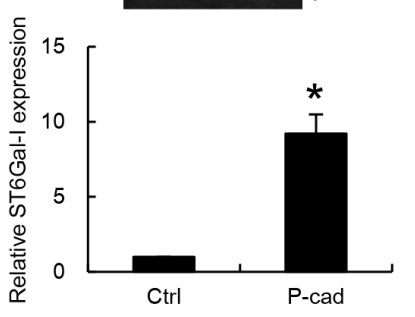

C

OVCA429

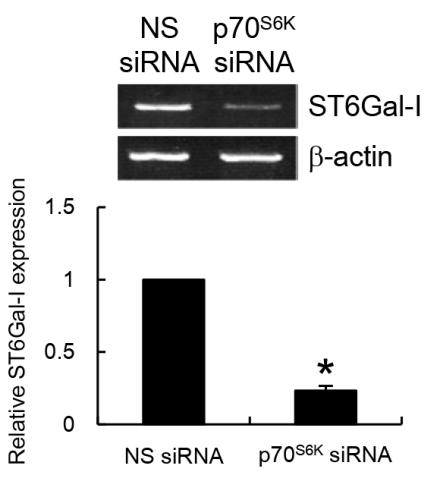

F

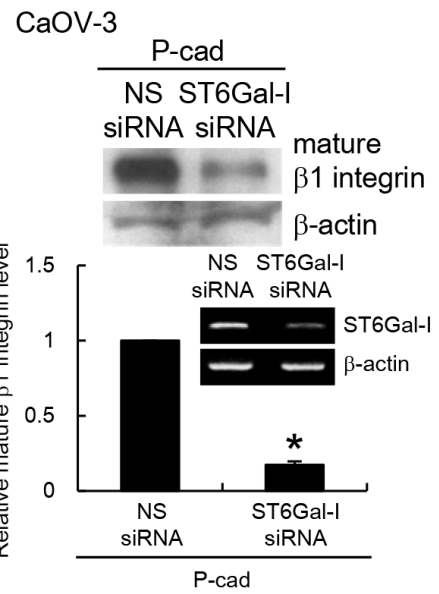

H

G

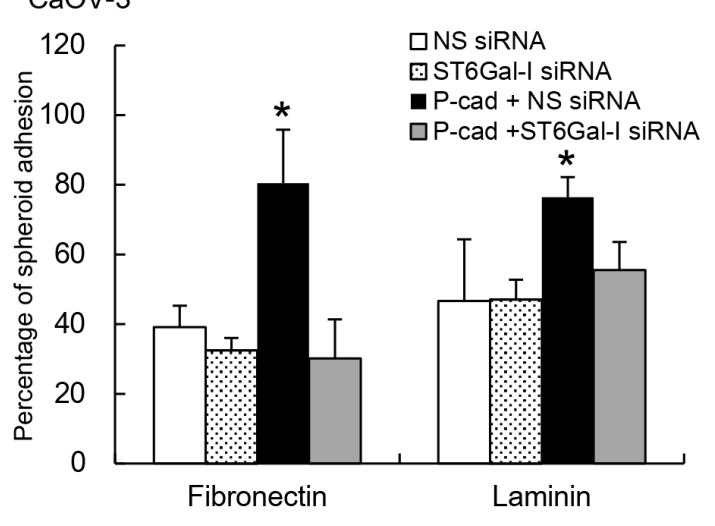

CaOV-3

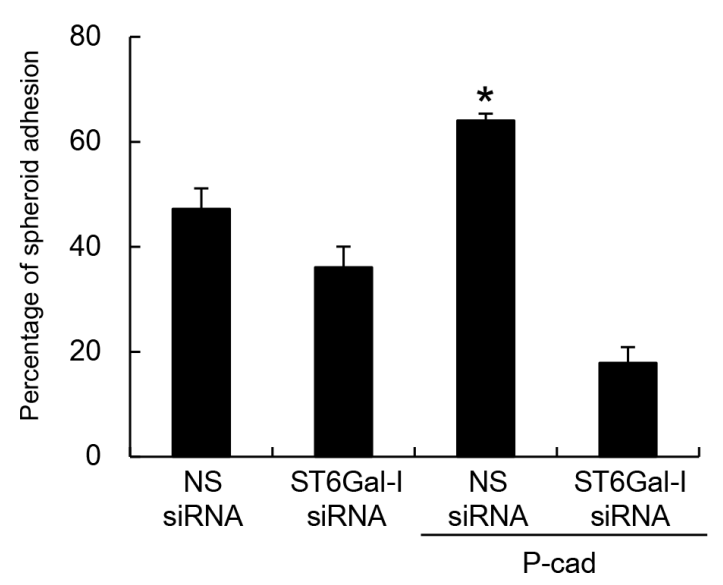

Figure 6: $\mathbf{p 7 0}^{\mathrm{S} 6 \mathrm{~K}}-\mathbf{P}$-cadherin signaling regulates $\boldsymbol{\beta 1}$ integrin maturation through ST6Gal-I. CaOV-3 spheroids were transfected with $(\mathbf{A})$ constitutively active $\mathrm{p} 70^{\mathrm{S} 6 \mathrm{~K}}\left(\mathrm{D}_{3} \mathrm{E}-\mathrm{E}_{389}\right)$ alone or (B) cotransfected with nonspecific (NS) siRNA or P-cadherin siRNA. OVCA429 spheroids were transfected with NS siRNA, (C) p70 ${ }^{\mathrm{S} 6 \mathrm{~K}}$ siRNA, or (D) P-cadherin siRNA. (E) CaOV-3 spheroids were stably transfected with P-cadherin. Total RNA was extracted and RT-PCR was carried out with the primer specific to ST6Gal-I. $\beta$-actin served as the control. Signal intensity was determined by densitometry and levels of ST6Gal-I were normalized against the $\beta$-actin control. CaOV-3 spheroids stably expressing P-cadherin were transfected with NS siRNA or ST6Gal-I siRNA. (F) The level of mature form of $\beta 1$ integrin in whole cell lysates was analyzed by Western blotting. The knockdown efficiency of ST6Gal-I siRNA was analyzed by RT-PCR (insert). In addition, spheroids were collected for the adhesion assay with $(\mathbf{G})$ fibronectin, laminin or $(\mathbf{H})$ mesothelial cells. The percentage of adherent spheroids was quantified after nonadherent spheroids were removed. Data are expressed as mean \pm S.D. ${ }^{*}, P<0.05$ vs. control, empty vector or NS siRNA expressing spheroids. 
involved in this process. These data indicate P-cadherin plays a role in the increased expression of ST6Gal-I by $\mathrm{p} 70^{\mathrm{S} 6 \mathrm{~K}}$ activation. Using spheroid adhesion assays, we further showed that $\alpha 2-6$ sialylation of $\beta 1$ integrin was required for the $\mathrm{P}$-cadherin-mediated adhesion to fibronectin, laminin (Figure 6G), and mesothelial cells (Figure 6H).

\section{P-cadherin-dependent ST6Gal-I induction is mediated by $\mathbf{p} 120$ catenin $\left(\mathbf{p 1 2 0} 0^{\mathrm{ctn}}\right)$}

To determine how P-cadherin interacts with ST6Gal-I at the molecular level, we evaluated the potential contributions of $\beta$-catenin and $\mathrm{p} 120^{\mathrm{ctn}}$, which are associated with the intracellular domain of $\mathrm{P}$-cadherin and are known to affect gene expression. We used siRNAs to knockdown $\beta$-catenin and p120 ctn expression in P-cadherinoverexpressing CaOV-3 spheroids. Knockdown of p120 ctn (Figure 7A, left), but not knockdown of $\beta$-catenin (Figure 7A, right), dramatically reduced the expression of mature $\beta 1$ integrin in $\mathrm{P}$-cadherin-overexpressing $\mathrm{CaOV}-3$ spheroids. Knockdown of p120 $0^{\text {ctn }}$ expression prevented the upregulation of ST6Gal-I in response to P-cadherin (Figure 7B). In OVCA429 spheroids, knockdown of p120 ctn , but not knockdown of $\beta$-catenin, had similar effects on $\beta 1$ integrin (Figure 7C) and ST6Gal-I (Figure 7D) expression. In addition, we observed an increased level of p120 ${ }^{\mathrm{ctn}}$ in $\mathrm{D}_{3} \mathrm{E}_{-\mathrm{E}_{389^{-}}}$(Figure 7E) and P-cadherin-expressing CaOV-3 spheroids (Figure 7F), but silencing of P-cadherin abolished this (Figure 7G). These results show the P-cadherin-ST6Gal-I interaction was mediated by canonical p $120^{\mathrm{ctn}}$ signaling.
A

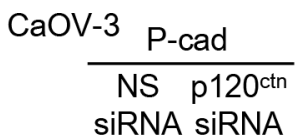

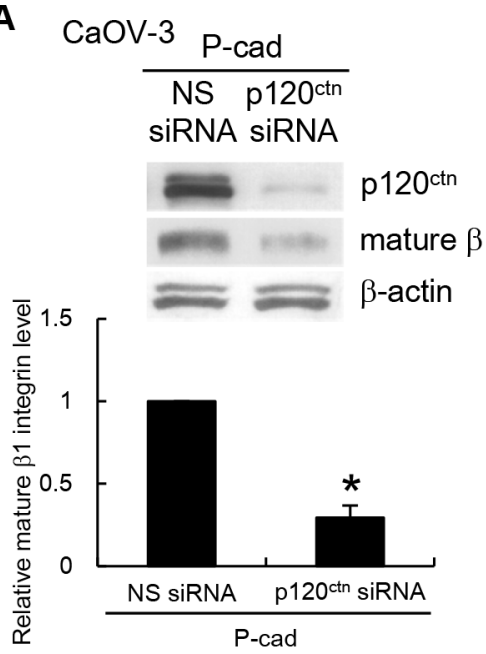

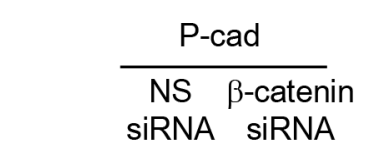

integrin

$\longrightarrow \quad \beta$-catenin

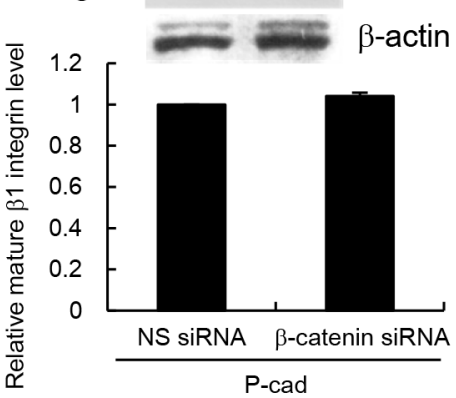

B
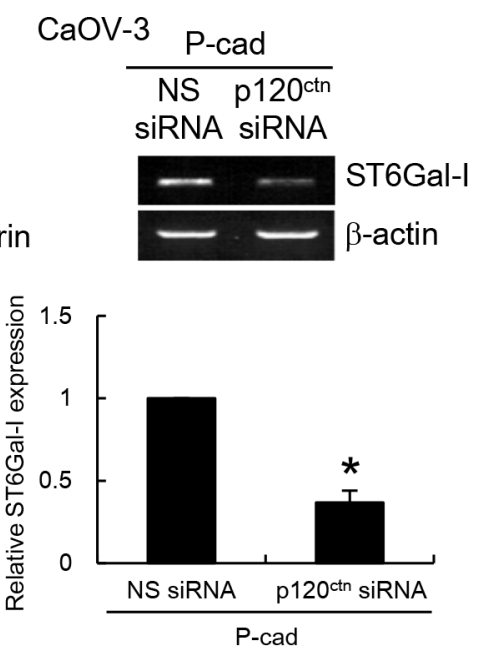

C
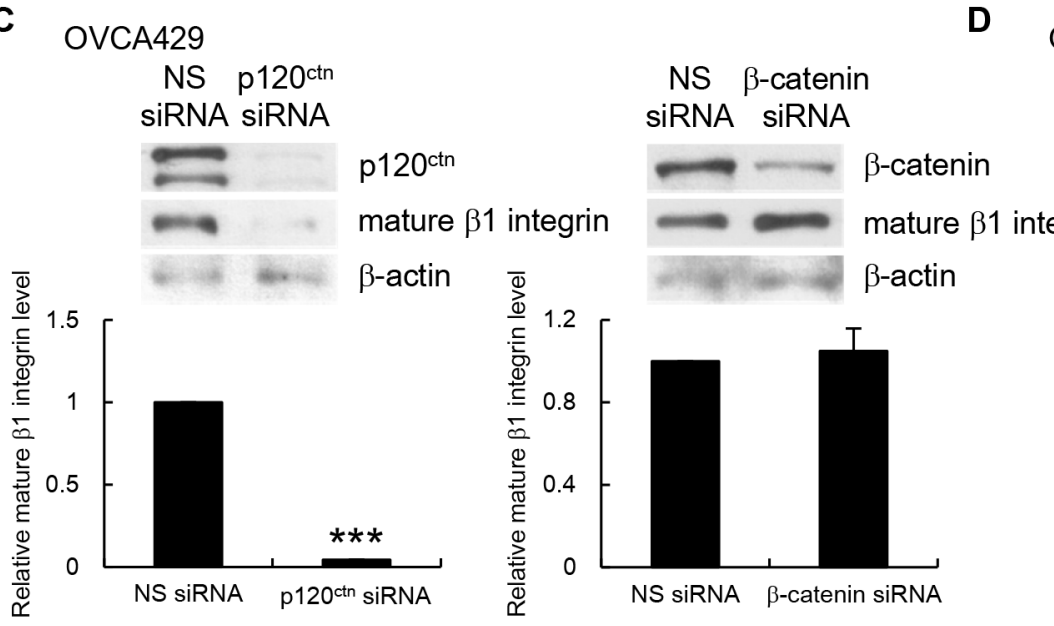

OVCA429
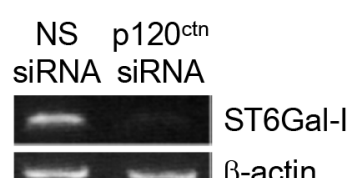

Figure 7: P-cadherin-ST6Gal-I dependent $\beta 1$ integrin maturation is mediated by $\mathbf{p} 120^{\mathrm{ctn}}$. CaOV-3 spheroids stably expressing P-cadherin or OVCA429 spheroids were transfected with nonspecific (NS) siRNA, p120 $0^{\mathrm{ctr}}$ siRNA, or $\beta$-catenin siRNA. $(\mathbf{A}, \mathbf{C})$ The level of the mature form of $\beta 1$ integrin in whole cell lysates was analyzed by Western blotting. (B, D) Total RNA was extracted and the level of ST6Gal-I was analyzed by RT-PCR.

(Continued) 
E

CaOV-3

empty
vector $D_{3} E-E_{389}$

$=\mathrm{p} 120^{\mathrm{ctn}}$

$\longrightarrow \beta$-actin

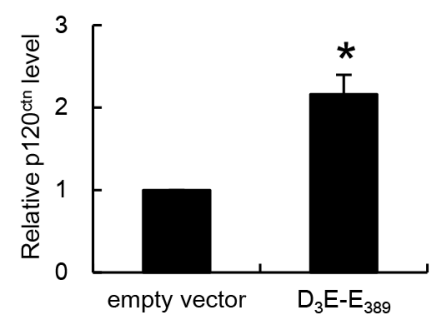

$\mathbf{F}$

CaOV-3

Ctrl P-cad
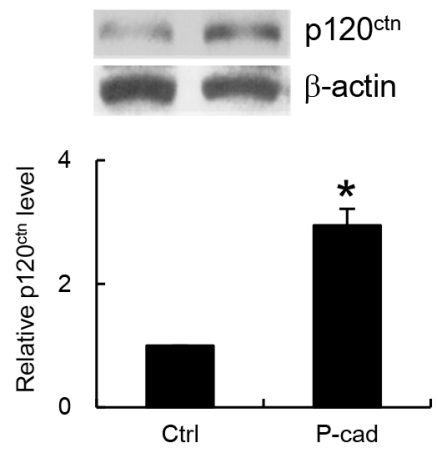

G

CaOV-3
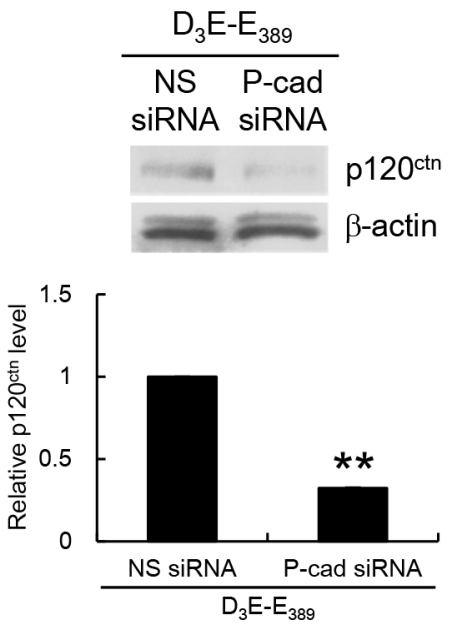

Figure 7: Whole cell lysates of CaOV3 spheroids $(\mathbf{E})$ expressing empty vector or constitutively active $\mathrm{p} 70^{\mathrm{S} 6 \mathrm{~K}}\left(\mathrm{D}_{3} \mathrm{E}-\mathrm{E}_{389}\right)$, or (F) stably expressing P-cadherin, or (G) coexpressing $\mathrm{D}_{3} \mathrm{E}_{-} \mathrm{E}_{389}$ with NS or P-cadherin siRNA were analyzed for the level of $120^{\mathrm{ctn}}$ by Western blotting. $\beta$-actin served as the control for both Western blotting and RT-PCR. Signal intensity was determined by densitometry and levels of the mature form of $\beta 1$ integrin, ST3Gal-I or p120 ${ }^{\mathrm{ctn}}$ were normalized against the $\beta$-actin control. Data are expressed as mean \pm S.D. *, $P<0.05$; **, $P<0.005 ; * * *, P<0.001$ vs. empty vector or NS siRNA expressing spheroids.

\section{p70 ${ }^{\mathrm{S} 6 \mathrm{~K}}$ inhibition reduces adhesion and peritoneal metastasis}

The data so far indicate that $\beta 1$ integrin is upregulated by P-cadherin upon $\mathrm{p} 70^{\mathrm{S} 6 \mathrm{~K}}$ activation and to induce adhesion in vitro. We further investigated the interplay between $\mathrm{p} 70^{\mathrm{S} 6 \mathrm{~K}}$, P-cadherin, and $\beta 1$-integrin in the metastatic process in ovarian cancer. We examined the effect of $\mathrm{p} 70^{\mathrm{s} 6 \mathrm{~K}}$, P-cadherin, and $\beta 1$ integrin shRNA on ovarian cancer spheroids growth in the peritoneal cavity using an orthotopic mouse model with advanced ovarian cancer [20]. Control mice or nonspecific shRNAtreated mice showed multiple tumors on the omentum, mesenterium and small bowel (Figure 8). The tumor burden as gauged by the number of disseminated tumor nodules was significantly fewer in mice injected with p $70^{\mathrm{S} 6 \mathrm{~K}}$ (62.6\% inhibition, $\left.P=0.024\right)$, P-cadherin (73.5\% inhibition, $P=0.047)$, and $\beta 1$ integrin (54.2\% inhibition, $P$ $=0.021)$ shRNA-expressing spheroids. These in vivo data further support the importance of a $\mathrm{p} 70^{\mathrm{S} 6 \mathrm{~K}}-\mathrm{P}$-cadherin- $\beta 1$ integrin signaling axis in ovarian cancer metastasis.

\section{DISCUSSION}

Understanding the early steps of metastasis is crucial to identify novel targets for cancer therapeutics. Peritoneal metastasis is a lethal progression of ovarian cancer, and determining the molecular mechanisms involved is a pressing need. Here for the first time, we provide evidence that $\mathrm{p} 70^{\mathrm{s} 6 \mathrm{~K}}$, a key intracellular signaling mediator of multiple growth factors in malignant ascites and is frequently activated in human ovarian cancer, plays a critical role in adhesion of ovarian cancer cells to the peritoneal mesothelium, which is one of the earliest steps in metastasis. This would suggest that $\mathrm{p} 70^{\mathrm{S} 6 \mathrm{~K}}$ might be as important in tumor progression as other very early genetic abnormalities, which could be targeted for cancer treatments. These types of treatment would be intriguing because current targeted therapies for ovarian cancer focus on counteracting the progression (e.g. vascular endothelial growth factor or angiogenesis) rather than the initiation of metastasis.

We also demonstrated a new mechanism of action of $\mathrm{p} 70^{\mathrm{s} 6 \mathrm{~K}}$ in peritoneal adhesion, which involved $\mathrm{P}$-cadherin and $\beta 1$ integrin as targets. This observation also expands on our previous findings. We previously detected significant levels of P-cadherin in the metastatic adenocarcinoma in omentum or peritoneum and on mesothelial cells, suggesting that P-cadherin may mediate tumor-mesothelial cell adhesion [21]. This function could be explained by the fact that P-cadherin is the predominant subtype expressed in the peritoneum and by the unique ability of cadherins to engage in homophilic (i.e., between the same cadherins) and heterotypic (i.e., between two different cell types) interactions [22, 23]. The involvement of $\beta 1$ integrin in ovarian tumorigenesis has also been supported by several studies [24]. Clinically, high $\beta 1$ integrin expression is indicative of a poor outcome [25]. Treatment with a $\beta 1$ integrin antibody either before disseminated tumors develop or after solid tumors are 
A
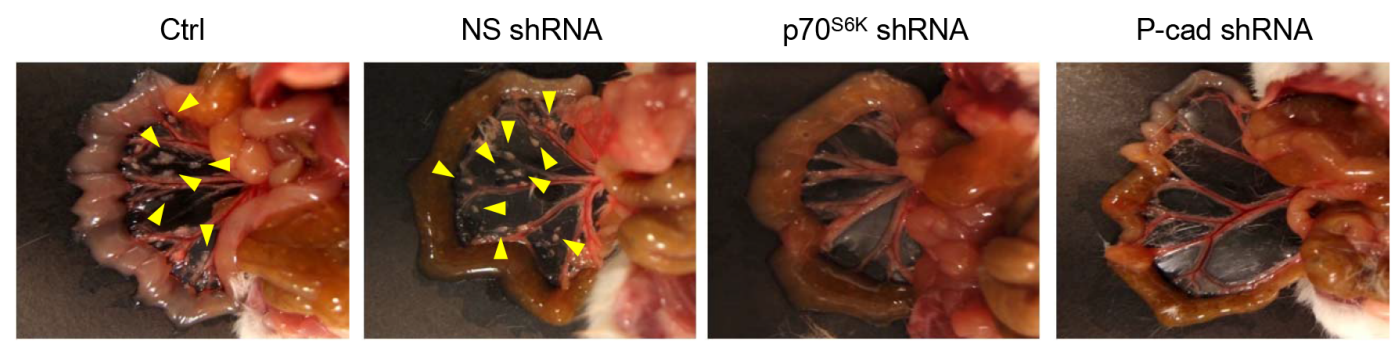

$\beta 1$ integrin shRNA
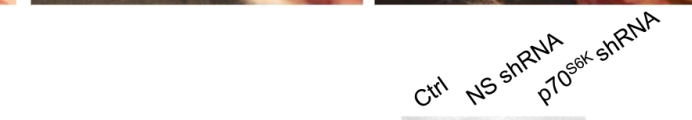

B
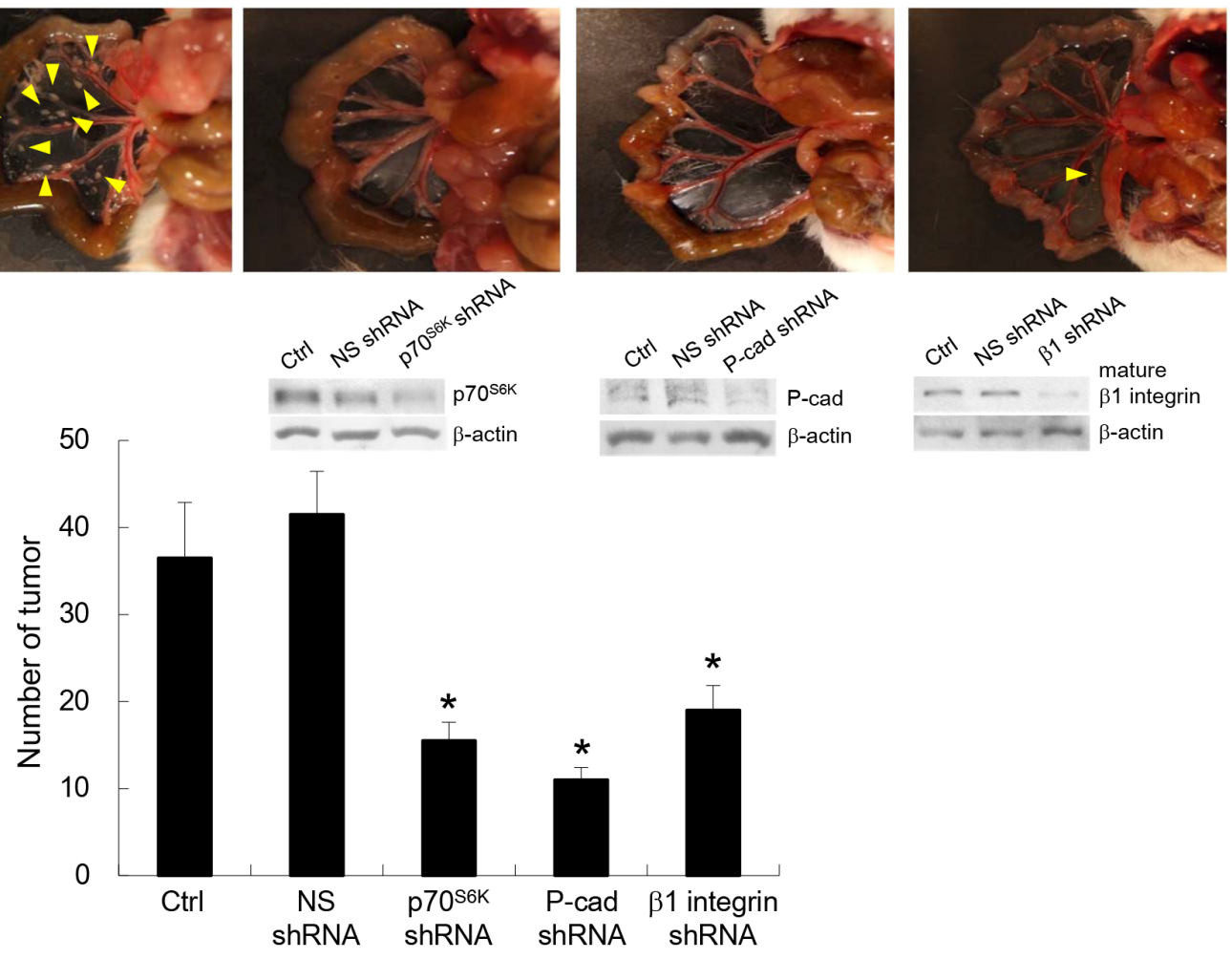

Figure 8: Inhibition of $\mathrm{p}^{\mathrm{s}}{ }^{\mathrm{s}}{ }_{\text {-P-cadherin- } \beta 1}$ integrin signaling reduces peritoneal metastasis in vivo. (A) Female NOD SCID mice were injected intraperitoneally with $1 \times 10^{7}$ OVCA429 cells (obtained from spheroid cultures) transduced with nonspecific (NS) shRNA, p $70^{\mathrm{s} 6 \mathrm{~K}}$ shRNA, P-cadherin shRNA, and $\beta 1$ integrin shRNA. They were sacrificed 15 weeks after injection. Representative views of the metastases in the peritoneal cavity are shown. Arrows indicate tumor. (B) Tumors were counted at autopsy. Data are expressed as mean \pm S.D. ${ }^{*}, P<0.05$ vs. NS shRNA expressing spheroids.

established within the peritoneal cavity have been shown to be effective in inhibiting ovarian cancer metastasis [26]. In addition to their involvement in the adhesion of ovarian cancer cells to peritoneal mesothelial cells, it is important to emphasize that both P-cadherin and $\beta 1$ integrin may activate 'outside-in signaling' to stimulate subsequent migration and invasion [27, 28].

The existence of interplay between members of different families of adhesion molecules has been previously suggested in other cellular systems. For example, $\mathrm{N}$-cadherin expression stimulates directional and collective cell migration by activating integrins [29]. Likewise, in squamous carcinoma cells, the signaling pathway between T-cadherin and $\beta 1$ integrin is important for aggressive invasion and distant metastasis [30]. The biological implication of this crosstalk in ovarian cancer is potentially of high functional significance because this fine-tuned mechanism ensures efficient coordination between adhesion systems, where spatial and temporal coordinated expression and activation of multiple receptors are more important for regulating cell adhesion than the intrinsic specificity of individual receptors [31-33]. In particular, expression of $\beta 1$ integrin could give ovarian cancer cells a selection advantage that allows them, upon displacement of the mesothelial cells, to attach to the underlying ECM. The expression of P-cadherin induces cell-matrix adhesion, which is consistent with the hypothesis that cadherins are master regulators of cell adhesion and are required for establishing diverse cell junctions [34].

One of the novel findings of the present study is that P-cadherin was shown to be an activator of ST6Gal-I synthesis. In many tissues or cell type, ST6Gal-I is differentially expressed. This suggests that the gene expression of ST6Gal-I could be controlled by specific promoters or corresponding transcriptional factors of the oncogene and tumor suppressor pathways to regulate ST6Gal-I expression [35]. For example, the Ras oncogene, liver-enriched factors HNF-1 and DBP, and transcription factors AP-1 and AP-2 have all been reported to participate in the transcriptional activity of ST6Gal-I [36-38]. This study is the first to demonstrate that ST6Gal-I is a target gene of P-cadherin, adding P-cadherin as a new member of transcriptional modulators of ST6Gal-I.

Our findings provide the first evidence of the crosstalk between P-cadherin and $\beta 1$ integrin is based 
on the regulation of $\beta 1$ integrin activation that occurs at the post-translation modification level. The rapidity with which $\beta 1$ integrin becomes activated could be the mechanism by which ovarian cancer cells can specifically and rapidly respond to environmental changes. Although mechanisms have not been fully elucidated, $\alpha 2-6$ sialylation could modify integrin-dependent cell responses by changing receptor conformation or by indirect mechanisms with other membrane-associated proteins [17]. Of interest, ST6Gal-I is overexpressed in many types of cancers including ovarian cancer and this upregulation correlates with increased metastatic potential and poor prognosis [39-41].

The experiments in this study examined spheroids that closely mimic conditions in vivo and could be of clinical importance. Increasing evidence indicates that ovarian carcinoma cells cultured as spheroids exhibit different proliferative and adhesive properties compared to monolayer cultures $[42,43]$. Our results suggest that targeting $\mathrm{p} 70^{\mathrm{S} 6 \mathrm{~K}}$ could provide the best approach to inhibiting the progression of ovarian cancer in its initial stage, including ovarian carcinomas that may be localized in the ovary but have malignant ascites or positive peritoneal washings, and also that have not been completely removed during surgery at the microscopic level.

Many inhibitors that target the $\mathrm{mTOR} / \mathrm{p} 70^{\mathrm{S} 6 \mathrm{~K}}$ pathway have been developed and some are currently being tested in clinical trials. For example, RAD001 (Everolimus) has been shown to be effective in delaying tumor progression and prolonging survival in both xenografts and transgenic mice models of ovarian cancer $[44,45]$. CCI-779 (Temsirolimus) tested in patients with malignant ovarian cancer resulted in the apparent reduction of ascites and decreased peritoneal dissemination of tumor cells [46]. NVP-BEZ235 could effectively inhibit growth of ovarian cancer cells even with platinum resistance and could prolong survival of mice with intraperitoneal ovarian tumors [47]. Furthermore, rapamycin and several of its analogs have been demonstrated to have synergistic cytotoxic effect with other chemotherapeutic agents on ovarian cancer [45, 48, 49]. Recent evidence suggests that $\mathrm{mTOR} / \mathrm{p} 70^{\mathrm{S} 6 \mathrm{~K}}$ signaling is overactivated in $\mathrm{p} 53$ deficient or mutant cells [50-52]. Alterations in p53 are common in advanced ovarian cancer [53]. The diverse types of p53 mutants make it difficult to develop a versatile $\mathrm{p} 53$-reactivating drug, but targeting the $\mathrm{mTOR} / \mathrm{p} 70^{\mathrm{S} 6 \mathrm{~K}}$ pathway could be an alternative strategy. Detailed tumor intervention studies and survival analyses on ovarian cancer treatments targeting this pathway certainly merit further investigation.

In summary, our study provides new findings show that $\mathrm{p} 70^{\mathrm{S} 6 \mathrm{~K}}$ increases peritoneal adhesion and dissemination of ovarian cancer. Our observation that activation of $\mathrm{P}$-cadherin $/ \beta 1$ integrin crosstalk promotes peritoneal metastasis of ovarian cancer indicates this signaling pathway could play a role in ovarian cancer malignancy. Because patient's prognosis depends on the tumor residue, it is critical to understand the molecular events that regulate metastasis. Our results should be a step in this direction and provide a strong rationale to explore the targeting of $\mathrm{p} 70^{\mathrm{s} 6 \mathrm{~K}}$ in the context of novel strategies against ovarian cancer dissemination.

\section{MATERIALS AND METHODS}

\section{Cell lines and cell culture}

Human ovarian CaOV-3 (a gift from Dr. Nelly Auersperg, University of British Columbia, Vancouver, B. C., Canada), OV-90 and OVCA429 cancer cell lines were maintained in M199:MCDB105 supplemented with $5 \%$ fetal bovine serum (Hyclone, Logan, UT, USA) at $37^{\circ} \mathrm{C}$ under $5 \% \mathrm{CO}_{2}$. To generate spheroids, cells were dissociated by trypsinization and plated on non-adhesive culture dishes as described [54]. Spheroids were collected for experiments after 36 to $48 \mathrm{~h}$. Each spheroid was about $100 \mu \mathrm{m}$ in diameter containing about 500-1,000 cells. Human peritoneal tissue was obtained from patients undergoing surgery for benign conditions. Mesothelial cells were isolated as described [55], and were cultured at $37^{\circ} \mathrm{C}$ for 2 to 3 days until a monolayer of polygonal cells had grown.

\section{siRNA, shRNA, and cDNA plasmids}

Specific siRNA oligonucleotides against $\mathrm{p} 70^{\mathrm{s} 6 \mathrm{~K}}$ (5'-GACAAAAUCCUCAAAUGUA-3'), P-cadherin (5'-GAGGGUGUCUUCGCUGUAG-3'), $\beta 1$ integrin (5'-CCACAGACA UUUACAUUAA-3'), ST6Gal-I (5'-ACUCAGAUAUCCCAAAGUG-3'), p120-catenin (5'-UAGCUGACCUCCUGACUAA-3'), $\beta$-catenin (5'-AAGUCCUGUAUGAGUGGG AAC-3'), and nonspecific duplex oligo (5'-GGCTACGTCCAGGAGCGCA-3') were obtained from Dharmacon (Lafayette, CO, USA). Transfection was performed using siLentFect (Bio-Rad, Hercules, CA, USA) according to the manufacturer's procedures. To stably attenuate expression of $\mathrm{p} 70^{\mathrm{S} 6 \mathrm{~K}}, \beta 1$ integrin, and $\mathrm{P}$-cadherin, we infected cells with lentivirus containing $\mathrm{p} 70^{\mathrm{S} 6 \mathrm{~K}}$ shRNA, $\beta 1$ integrin shRNA or P-cadherin shRNA, or nonspecific shRNA as a control. Lentivrus-infected cells were selected for 72 hours in medium containing $1 \mu \mathrm{g} / \mathrm{ml}$ puromycin (Invitrogen, San Diego, CA, USA). To ectopically express active $\mathrm{p} 70^{\mathrm{S} 6 \mathrm{~K}}\left(\mathrm{D}_{3} \mathrm{E}-\mathrm{E}_{389}\right)$ in CaOV-3 cells, we used a myc-tagged cDNA encoding the constitutively active $\mathrm{p} 70^{\mathrm{S} 6 \mathrm{~K}}$ (generously given by Dr. George Thomas, Genome Research Institute, University of Cincinnati, OH, USA). 


\section{Cancer spheroid adhesion assays}

For measurement of adhesion to human peritoneal mesothelial cells, fluorescent-labeled spheroids were overlaid onto a monolayer of confluent primary human mesothelial cells coated on a 24-well plate and allowed to attach for 1 to $5 \mathrm{~h}$ before counting. For measurement of adhesion to ECM components, plates were first coated with fibronectin, laminin, vitronectin and collagen I $(10 \mu \mathrm{g} / \mathrm{ml})$ according to the manufacturer's instructions (BD Biosciences, San Jose, CA, USA), spheroids were then added and allowed to attach for 1 to $5 \mathrm{~h}$ before counting. For the inhibition experiments, spheroids were pretreated with a neutralizing antibody to $\beta 1$ integrin (clone JB1A; 1:100) (Chemicon, Chandlers Ford, UK) at $37^{\circ} \mathrm{C}$ for $30 \mathrm{~min}$ prior to incubation with mesothelial cells or the different ECM components. The total number of spheroids in each well was counted prior to removal of nonadherent spheroids. Nonadherent spheroids were removed by gentle washing with PBS. The remaining adhered spheroids were fixed and counted. The percentage of adhered spheroid was calculated by dividing the number of spheroids adhering on the mesothelium or ECM components by the total number of spheroids in each well before washing.

\section{Reverse transcription-PCR}

Total RNA was isolated using Trizol (Invitrogen) according to the manufacturer's instructions. Total RNA (500 ng) was reverse transcribed using a Firststrand Reverse Transcription Kit (Invitrogen), and PCR was performed with a set of primers: ST6Gal-I, sense 5'- TATCGTAAGCTGCACCCCAATC-3', anti-sense 5'-TTAGCAGTGAATG GTCCGGAAG-3'; and $\beta$-actin, sense 5'-TCACCGAGGCCCCTCTGAACCCTA-3', anti-sense 5'-GGCAGTAATCTCCTTCTGCATCCT-3'. The number of amplification cycles, during which the PCR product formation was limited by the template concentration was determined in pilot experiments. The mRNA levels of target genes were normalized to that of $\beta$-actin.

\section{Western blotting}

Cells were harvested in SDS sample buffer $(65 \mathrm{mM}$ Tris-Cl pH 6.8, 2\% SDS, 10\% glycerol) supplemented with protease inhibitors $(1 \mu \mathrm{g} / \mathrm{ml}$ aprotinin, $1 \mu \mathrm{g} / \mathrm{ml}$ leupeptin, $1 \mu \mathrm{g} / \mathrm{ml}$ pepstatin $\mathrm{A}, 1 \mathrm{mM}$ phenylmethyl sulfonyl), $1 \mathrm{mM}$ sodium orthovanadate and $1 \mathrm{mM}$ sodium fluoride) and quantified using a DC protein assay kit (Bio-Rad). Equal amounts of protein were separated on SDS-polyacrylamide gels and transferred to nitrocellulose membrane. Membranes were then blocked and probed with the following primary antibodies: anti-c-myc (clone 9E10; 1:1,500), anti-phospho-p70 $0^{\mathrm{S} 6 \mathrm{~K}}$ (Thr389; 1:1,000), anti-p70 ${ }^{\mathrm{s} 6 \mathrm{~K}} \quad(1: 1,000)$, anti-phospho-S6 (Ser235/236;
1:1,000), anti-S6 (1:1,000) (Cell Signaling, Beverley, MA, USA), anti- $\beta 1$ integrin $(1: 1,000)$ (Chemicon, Chandlers Ford, UK), anti- $\beta$-catenin $(1: 2,000)$, anti-p120 $0^{\mathrm{ctn}}(1: 1,000)$, anti-P-cadherin (1:1000) (Transduction Laboratories, Lexington, KY, USA) and anti- $\beta$-actin $(1: 2,000)$ (Sigma, St Louis, MO, USA). Western blot membranes were visualized using an enhanced chemiluminescent substrate for detection of horseradish peroxidase (Amersham, Little Chalfont, UK).

\section{Mouse model of ovarian cancer metastasis}

4-6 week-old female NOD SCID mice (Charles River Laboratories, Wilmington, MA) were used ( $\mathrm{n}=$ 3 per group), and the experiment was conducted twice. $1 \times 10^{7}$ cells from the spheroid cultures were suspended in $0.1 \mathrm{ml}$ Hanks' Balanced salt solution and were injected intraperitoneally into the peritoneal cavity. The mice were sacrificed and the numbers of disseminated tumor nodules within the peritoneal cavity were counted. All animal studies were performed using protocols approved by the University of Hong Kong Institutional Animal Care and Use Committee.

\section{Statistical analyses}

$P$ values were based upon Student's t test using GraphPad Prism (San Diego, CA, USA). $P<0.05$ was considered to be statistically significant on the basis of at least three independent sets of experiments.

\section{ACKNOWLEDGEMENTS}

This research was supported by the Hong Kong Research Grant Council grants 782111 and 17122014 (to ASTW); ASTW is a recipient of the Croucher Senior Research Fellowship.

\section{Conflict of interest}

The authors declare that they have no conflicts of interest.

\section{REFERENCES}

1. Siegel R, Naishadham D and Jemal A. Cancer statistics, 2012. CA Cancer J Clin. 2012; 62:10-29.

2. Ip CK and Wong AS. Exploiting p70 S6 kinase as a target for ovarian cancer. Expert Opin Ther Targets. 2012; 16:619-630.

3. Altomare DA, Wang HQ, Skele KL, De Rienzo A, Klein-Szanto AJ, Godwin AK and Testa JR. AKT and mTOR phosphorylation is frequently detected in ovarian cancer and can be targeted to disrupt ovarian tumor cell growth. Oncogene. 2004; 23:5853-5857. 
4. Zhou HY and Wong AST. Activation of p70(S6K) induces expression of matrix metalloproteinase 9 associated with hepatocyte growth factor-mediated invasion in human ovarian cancer cells. Endocrinology. 2006; 147:2557-2566.

5. Castellvi J, Garcia A, Rojo F, Ruiz-Marcellan C, Gil A, Baselga $J$ and Cajal SRY. Phosphorylated 4E binding protein 1: A hallmark of cell signaling that correlates with survival in ovarian cancer. Cancer. 2006; 107:1801-1811.

6. Pon YL, Zhou HY, Cheung ANY, Ngan HYS and Wong AST. p70 S6 kinase promotes epithelial to mesenchymal transition through Snail induction in ovarian cancer cells. Cancer Res. 2008; 68:6524-6532.

7. Hynes RO. Integrins: bidirectional, allosteric signaling machines. Cell. 2002; 110:673-687.

8. Sundfeldt K. Cell-cell adhesion in the normal ovary and ovarian tumors of epithelial origin; an exception to the rule. Mol Cell Endocrinol. 2003; 202:89-96.

9. Elmasri WM, Casagrande G, Hoskins E, Kimm D and Kohn EC. Cell adhesion in ovarian cancer. Cancer Treat Res. 2009; 149:297-318.

10. Sowter HM, Corps AN and Smith SK. Hepatocyte growth factor (HGF) in ovarian epithelial tumour fluids stimulates the migration of ovarian carcinoma cells. Int J Cancer. 1999; 83:476-480.

11. Sawada K, Radjabi AR, Shinomiya N, Kistner E, Kenny H, Becker AR, Turkyilmaz MA, Salgia R, Yamada SD, Vande Woude GF, Tretiakova MS and Lengyel E. c-Met overexpression is a prognostic factor in ovarian cancer and an effective target for inhibition of peritoneal dissemination and invasion. Cancer Res. 2007; 67:1670-1679.

12. Wong AS, Pelech SL, Woo MM, Yim G, Rosen B, Ehlen T, Leung PC and Auersperg N. Coexpression of hepatocyte growth factor-Met: an early step in ovarian carcinogenesis? Oncogene. 2001; 20:1318-1328.

13. Wong AST, Roskelley CD, Pelech S, Miller D, Leung PCK and Auersperg N. Progressive changes in Met-dependent signaling in a human ovarian surface epithelial model of malignant transformation. Exp Cell Res. 2004; 299:248-256.

14. Moser TL, Pizzo SV, Bafetti LM, Fishman DA and Stack MS. Evidence for preferential adhesion of ovarian epithelial carcinoma cells to type I collagen mediated by the alpha2beta1 integrin. Int J Cancer. 1996; 67:695-701.

15. Wilson AP. Mesothelial cells stimulate the anchorageindependent growth of human ovarian tumour cells. Br J Cancer. 1989; 59:876-882.

16. Tozer EC, Hughes PE and Loftus JC. Ligand binding and affinity modulation of integrins. Biochem Cell Biol. 1996; 74:785-798.

17. Bellis SL. Variant glycosylation: an underappreciated regulatory mechanism for beta1 integrins. Biochim Biophys Acta. 2004; 1663:52-60.

18. Semel AC, Seales EC, Singhal A, Eklund EA, Colley KJ and Bellis SL. Hyposialylation of integrins stimulates the activity of myeloid fibronectin receptors. J Biol Chem. 2002; 277:32830-32836.

19. Seales EC, Jurado GA, Singhal A and Bellis SL. Ras oncogene directs expression of a differentially sialylated, functionally altered beta1 integrin. Oncogene. 2003; 22:7137-7145.

20. Shaw TJ, Senterman MK, Dawson K, Crane CA and Vanderhyden BC. Characterization of intraperitoneal, orthotopic, and metastatic xenograft models of human ovarian cancer. Mol Ther. 2004; 10:1032-1042.

21. Cheung LW, Mak AS, Cheung AN, Ngan HY, Leung PC and Wong AS. P-cadherin cooperates with insulin-like growth factor-1 receptor to promote metastatic signaling of gonadotropin-releasing hormone in ovarian cancer via p120 catenin. Oncogene. 2011; 30:2964-2974.

22. Gumbiner BM. Regulation of cadherin-mediated adhesion in morphogenesis. Nat Rev Mol Cell Biol. 2005; 6:622-634.

23. Takeichi M. Morphogenetic roles of classic cadherins. Curr Opin Cell Biol. 1995; 7:619-627.

24. Burleson KM, Hansen LK and Skubitz AP. Ovarian carcinoma spheroids disaggregate on type I collagen and invade live human mesothelial cell monolayers. Clin Exp Metastasis. 2004; 21:685-697.

25. Muller-Klingspor V, Hefler L, Obermair A, Kaider A, Breitenecker G, Leodolte S and Kohlberger P. Prognostic value of beta1-integrin (=CD29) in serous adenocarcinomas of the ovary. Anticancer Res. 2001; 21:2185-2188.

26. Mitra AK, Sawada K, Tiwari P, Mui K, Gwin K and Lengyel E. Ligand-independent activation of c-Met by fibronectin and alpha(5)beta(1)-integrin regulates ovarian cancer invasion and metastasis. Oncogene. 2011; 30:1566-1576.

27. Cheung LW, Leung PC and Wong AS. Cadherin switching and activation of p120 catenin signaling are mediators of gonadotropin-releasing hormone to promote tumor cell migration and invasion in ovarian cancer. Oncogene. 2010; 29:2427-2440.

28. Buczek-Thomas JA, Chen $\mathrm{N}$ and Hasan $\mathrm{T}$. Integrin-mediated adhesion and signalling in ovarian cancer cells. Cell Signal. 1998; 10:55-63.

29. Ouyang M, Lu S, Kim T, Chen CE, Seong J, Leckband DE, Wang F, Reynolds AB, Schwartz MA and Wang Y. $\mathrm{N}$-cadherin regulates spatially polarized signals through distinct p120ctn and beta-catenin-dependent signalling pathways. Nat Commun. 2013; 4:1589.

30. Mukoyama Y, Utani A, Matsui S, Zhou S, Miyachi Y and Matsuyoshi N. T-cadherin enhances cell-matrix adhesiveness by regulating betal integrin trafficking in cutaneous squamous carcinoma cells. Genes Cells. 2007; 12:787-796.

31. Marsden M and DeSimone DW. Integrin-ECM interactions regulate cadherin-dependent cell adhesion and are required for convergent extension in Xenopus. Curr Biol. 2003; 13:1182-1191. 
32. Martinez-Rico C, Pincet F, Thiery JP and Dufour S. Integrins stimulate E-cadherin-mediated intercellular adhesion by regulating Src-kinase activation and actomyosin contractility. J Cell Sci. 2010; 123:712-722.

33. Yano H, Mazaki Y, Kurokawa K, Hanks SK, Matsuda M and Sabe H. Roles played by a subset of integrin signaling molecules in cadherin-based cell-cell adhesion. J Cell Biol. 2004; 166:283-295.

34. Niessen CM and Gottardi CJ. Molecular components of the adherens junction. Biochim Biophys Acta. 2008; 1778:562-571.

35. Dall'Olio F. The sialyl-alpha2,6-lactosaminyl-structure: biosynthesis and functional role. Glycoconj J. 2000; 17:669-676.

36. Le Marer N, Laudet V, Svensson EC, Cazlaris H, Van Hille B, Lagrou C, Stehelin D, Montreuil J, Verbert A and Delannoy P. The c-Ha-ras oncogene induces increased expression of beta-galactoside alpha-2, 6-sialyltransferase in rat fibroblast (FR3T3) cells. Glycobiology. 1992; 2:49-56

37. Svensson EC, Soreghan B and Paulson JC. Organization of the beta-galactoside alpha 2,6-sialyltransferase gene. Evidence for the transcriptional regulation of terminal glycosylation. J Biol Chem. 1990; 265:20863-20868.

38. Vandamme V, Cazlaris H, Le Marer N, Laudet V, Lagrou C, Verbert A and Delannoy P. Comparison of sialyland alpha-1,3-galactosyltransferase activity in NIH3T3 cells transformed with ras oncogene: increased beta-galactoside alpha-2,6-sialyltransferase. Biochimie. 1992; 74:89-99.

39. Christie DR, Shaikh FM, Lucas JAt, Lucas JA 3rd and Bellis SL. ST6Gal-I expression in ovarian cancer cells promotes an invasive phenotype by altering integrin glycosylation and function. J Ovarian Res. 2008; 1:3.

40. Dall'Olio F and Chiricolo M. Sialyltransferases in cancer. Glycoconj J. 2001; 18:841-850.

41. Schultz MJ, Swindall AF, Wright JW, Sztul ES, Landen CN and Bellis SL. ST6Gal-I sialyltransferase confers cisplatin resistance in ovarian tumor cells. J Ovarian Res. 2013; 6:25.

42. Tang MK, Zhou HY, Yam JW and Wong AS. c-Met overexpression contributes to the acquired apoptotic resistance of nonadherent ovarian cancer cells through a cross talk mediated by phosphatidylinositol 3-kinase and extracellular signal-regulated kinase 1/2. Neoplasia. 2010; 12:128-138.

43. Zietarska M, Maugard CM, Filali-Mouhim A, Alam-Fahmy M, Tonin PN, Provencher DM and Mes-Masson AM. Molecular description of a 3D in vitro model for the study of epithelial ovarian cancer (EOC). Mol Carcinog. 2007; 46:872-885.

44. Mabuchi S, Altomare DA, Cheung M, Zhang L, Poulikakos PI, Hensley HH, Schilder RJ, Ozols RF and Testa JR. RAD001 inhibits human ovarian cancer cell proliferation, enhances cisplatin-induced apoptosis, and prolongs survival in an ovarian cancer model. Clinical cancer research : an official journal of the American Association for Cancer Research. 2007; 13:4261-4270.

45. Mabuchi S, Altomare DA, Connolly DC, Klein-Szanto A, Litwin S, Hoelzle MK, Hensley HH, Hamilton TC and Testa JR. RAD001 (Everolimus) delays tumor onset and progression in a transgenic mouse model of ovarian cancer. Cancer Res. 2007; 67:2408-2413.

46. Takano M, Kikuchi Y, Kudoh K, Goto T, Furuya K, Kikuchi R, Kita T, Fujiwara K, Shiozawa T and Aoki D. Weekly administration of temsirolimus for heavily pretreated patients with clear cell carcinoma of the ovary: a report of six cases. International journal of clinical oncology. 2011; 16:605-609.

47. Santiskulvong C, Konecny GE, Fekete M, Chen KY, Karam A, Mulholland D, Eng C, Wu H, Song M and Dorigo O. Dual targeting of phosphoinositide 3-kinase and mammalian target of rapamycin using NVP-BEZ235 as a novel therapeutic approach in human ovarian carcinoma. Clinical cancer research : an official journal of the American Association for Cancer Research. 2011; 17:2373-2384.

48. Huynh H, Teo CC and Soo KC. Bevacizumab and rapamycin inhibit tumor growth in peritoneal model of human ovarian cancer. Molecular cancer therapeutics. 2007; 6:2959-2966.

49. Piha-Paul SA, Wheler JJ, Fu S, Levenback C, Lu K, Falchook GS, Naing A, Hong DS, Tsimberidou AM and Kurzrock R. Advanced gynecologic malignancies treated with a combination of the VEGF inhibitor bevacizumab and the mTOR inhibitor temsirolimus. Oncotarget. 2014; 5:1846-1855.

50. Comas M, Toshkov I, Kuropatwinski KK, Chernova OB, Polinsky A, Blagosklonny MV, Gudkov AV and Antoch MP. New nanoformulation of rapamycin Rapatar extends lifespan in homozygous p53-/- mice by delaying carcinogenesis. Aging. 2012; 4:715-722.

51. Komarova EA, Antoch MP, Novototskaya LR, Chernova OB, Paszkiewicz G, Leontieva OV, Blagosklonny MV and Gudkov AV. Rapamycin extends lifespan and delays tumorigenesis in heterozygous p53+/mice. Aging. 2012; 4:709-714.

52. Leontieva OV, Novototskaya LR, Paszkiewicz GM, Komarova EA, Gudkov AV and Blagosklonny MV. Dysregulation of the mTOR pathway in p53-deficient mice. Cancer biology \& therapy. 2013; 14:1182-1188.

53. Romero I and Bast RC Jr. Minireview: human ovarian cancer: biology, current management, and paths to personalizing therapy. Endocrinology. 2012; 153:1593-1602.

54. Iwanicki MP, Davidowitz RA, Ng MR, Besser A, Muranen T, Merritt M, Danuser G, Ince TA and Brugge JS. Ovarian cancer spheroids use myosin-generated force to clear the mesothelium. Cancer Discov. 2011; 1:144-157.

55. Yung S, Li FK and Chan TM. Peritoneal mesothelial cell culture and biology. Perit Dial Int. 2006; 26:162-173. 